\title{
Design of Adaptive Controllers based on Christoffel Symbols of First Kind
}

\author{
Juan Ignacio Mulero-Martínez \\ Technical Universty of Cartagena \\ Spain
}

\section{Introduction}

The present chapter is aimed at systematically exposing the reader to certain modern trends in designing advanced robot controllers. More specifically, it focuses on a new and improved method for building suitable adaptive controllers guaranteeing asymptotic stability. It covers the complete design cycle, while providing detailed insight into most critical design issues of the different building blocks. In this sense, it takes a more global design perspective in jointly examining the design space at control level as well as at the architectural level.

The primary purpose is to provide insight and intuition into adaptive controllers based on Christoffel symbols of first kind for a serial-link robot arm, (Mulero-Martínez, 2007a). These controllers are referred to as static since the positional dependence of the nonlinear functions. In this context, the preferred method of nonlinear compensation is the method of building emulators. Often, however, the full power of the method is overlooked, and very few works deal with these techniques at the level of detail that the subject deserves. As a result, the chapter fills that gap and includes the type of information required to help control engineers to apply the method to robot manipulators. Developed in this chapter are several deep connections between dynamics analysis and implementation emphasizing the powerful adaptive methods that emerge when separate techniques from each area are properly assembled in a larger context.

After beginning with a comprehensive presentation of the fundamentals of these techniques, the chapter addresses the problem of factorization of the Coriolis/centripetal matrix, (Mulero-Martinez, 2009). This aspect is crucial when designing non-linear compensators by emulation. At this point, it is provided a concise and didactically structured description of the design of emulators as matters stand, (Mulero-Martinez, 2006). Specifically, emulators are split up into sub-emulators to improve and simplify the design of controllers while making faster the updating of parameters. From a practical point of view, the implementation is developed by resorting to parametric structures. This means to obtain a set of system's own function as regression functions.

Most of the adaptive schemes start from the notable property of linearity in the parameters, which lead naturally to equivalent structures when designing emulators for the nonlinear terms. When the linearity in the parameters (LIP) is considered as a first assumption in the 
development of adaptive schemes, it is clear that there exists a strong connection to the LIP emulators formulated in terms of a regression matrix and a vector of parameters. The main difference between standard adaptive schemes and the proposed approach stems from the idea of developing efficient controllers. The present work is aimed by attempts to mitigate the "curse of dimensionality" by exploiting the representation properties associated with the matrix of Coriolis/centripetal effects. By recalling the connection between LIP representation of robot manipulators and LIP adaptive emulators, it can be asserted that standard scheme matches perfectly with a dynamic emulator. Thus, the regression matrix, depend not only on the position joint variables but also on the velocity and acceleration variables.

As regards to the control, a novel theorem guarantees the stability for the whole system and is based on the Lyapunov energy. The proof is generalized to cope with a realistic case where both a functional reconstruction error and an external disturbance are present. It should be observed that the functional reconstruction error is caused by not using a number of regression functions appropiately distributed in the space. As a result, these considerations lead to a quite different approach, since it is required to analyze the initial conditions of the errors to guarantee the validity of the approximation. The specification of a range of validity causes that the stability holds only inside a compact set. As a consequence, the proof guarantees semi-global stability as opposed to the standard schemes where the stability is attained in the whole state space, in a global sense. Apart from these considerations, a number of remarks have been made to address some special aspects such as the boundedness of the parameters, the ultimately uniformly boundedness of all the signals and the stability in the ideal case.

The main benefit of the proposed controller is that it allows to derive tuning laws only for inertia, gravitational and frictional parameters. The Coriolis parameters are not necessary to be used because of the approximation based on Christoffel symbols. This is very useful to implement adaptive controllers since the number of nodes diminishes and the computational performance improves. Previously, an extensive analysis of the mechanical properties for a robot has been discussed. The regression functions for the adaptive controller depend on the non-linear functions associated with the inertia matrix, and therefore, a discretization of positions could be done for the inertia matrix. This is a very useful aspect because the position space for a revolute robot is compact and in consequence, the number of nodes is limited to approximate a non-linear function.

The plan of the chapter is as follows. In section 2 the representation properties for the Coriolis/centripetal matrix are analysed. An interpretation for the Coriolis/centripetal matrix is presented and the description by means of the Christoffel symbols of first kind and fundamental matrices are provided. In section 3, emulators are used to approximate the non-linearities of a robot using the properties presented in the previous section and the Kronecker product. The next section presents the design of the adaptive controller in terms of a control law and a parameter updating law. This section concludes with a theorem that guarantees the stability for the whole system and is based on the Lyapunov energy. Finally an example of a 2-dof robot arm is used to illustrate the theorem.

\section{Representation of the Coriolis/Centripetal Matrix. Fundamental Matrices}

In this section some notions regarding the representation of the Coriolis/centripetal 
matrices are introduced. All the ideas presented here constitute an original contribution and have many interesting implications in the field of robotics. To this end, fundamental matrices are introduced and described in terms of their structure. Moreover, some emerging properties are analyzed, allowing one to build the Coriolis/centripetal matrix in a simple way. Let start with the definition of the matrix $M_{D}$ which from now on will be called the inertia derivative matrix.

\section{Definition 1:}

$$
M_{D}(q, x)=\sum_{j=1}^{n} \frac{\partial M(q)}{\partial q_{j}} x e_{j}^{T}
$$

where $\mathrm{M}(\mathrm{q})$ is a generalized inertia matrix of dimension $\mathrm{n} \times \mathrm{n}$ a unitary vector of dimension $n$ with a value 1 in the position $j$ and $x$ is an arbitrary vector of dimension $n$. It is noted that if $x$ represents the generalized velocity vector, the matrix $M_{D}$ will stand for the gradient of the generalized momentum with respect to the position coordinates $q$. This means that the gradient of the kinetic energy as a quadratic form $\frac{1}{2} x^{T} \mathrm{M}(\mathrm{q}) \mathrm{x}$ relative to the joint position can be written as $\frac{1}{2} M_{D}^{T}(q, x) x$. Another representation of $M_{D}$ is showed below.

Property 1: The matrix $M_{D}(q, x)$ can be expressed as

$$
\mathrm{M}_{\mathrm{D}}(\mathrm{q}, \mathrm{x})=\sum_{\mathrm{i}=1}^{\mathrm{n}} \frac{\partial \mathrm{M}_{\mathrm{i}}}{\partial \mathrm{q}} \mathrm{x}_{\mathrm{i}}
$$

Proof: It is very easy to show that $\frac{\partial \mathrm{M}(\mathrm{q})}{\partial \mathrm{q}_{j}} \mathrm{xe}_{\mathrm{j}}^{\mathrm{T}}=\sum_{\mathrm{i}=1}^{\mathrm{n}} \frac{\partial \mathrm{M}_{\mathrm{i}}}{\partial \mathrm{q}_{j}} \mathrm{x}_{\mathrm{i}} \mathrm{e}_{\mathrm{j}}^{\mathrm{T}}$ since the following intermediate equation is obtained

$$
\frac{\partial \mathrm{M}(\mathrm{q})}{\partial \mathrm{q}_{j}} \mathrm{xe}_{\mathrm{j}}^{\mathrm{T}}=\left(\sum_{\mathrm{i}=1}^{\mathrm{n}} \frac{\partial \mathrm{M}_{\mathrm{i}}}{\partial \mathrm{q}_{j}} \mathrm{e}_{\mathrm{i}}^{\mathrm{T}}\right) \mathrm{xe}_{\mathrm{j}}^{\mathrm{T}}=\sum_{\mathrm{i}=1}^{\mathrm{n}} \frac{\partial \mathrm{M}_{\mathrm{i}}}{\partial \mathrm{q}_{\mathrm{j}}} \mathrm{x}_{\mathrm{i}} \mathrm{e}_{\mathrm{j}}^{\mathrm{T}}
$$

Using the definition 1 and the identity (3) the hypothesis of the property is concluded

$$
M_{D}(q, x)=\sum_{i=1}^{n} \sum_{j=1}^{n} \frac{\partial M_{i}}{\partial q_{j}} x_{i} e_{j}^{T}=\sum_{i=1}^{n} \frac{\partial M_{i}}{\partial q} x_{i}
$$

Q.E.D.

Now a new matrix will be introduced and from now on will be called as inertia velocity matrix, playing a central role in the representation theory.

Definition 2: Let define $M_{v}(q, x)$ in the following way

$$
M_{v}(q, x)=\left(\frac{\partial M_{1}}{\partial q} x, \ldots, \frac{\partial M_{n}}{\partial q} x\right)=\sum_{i=1}^{n} \frac{\partial M_{i}}{\partial q} x_{i}^{T}
$$


The inertia velocity matrix $M_{v}(q, x)$ receives its name from the fact that when $x=\dot{q}$, the term $M_{v}(q, \dot{q})$ will be the time differentiation of the generalized inertia matrix, i.e. $\dot{M}(q)$. The following property provides an alternative way to write the matrix $M_{V}$.

Property 2: The inertia velocity matrix can be also expressed as

$$
M_{v}(q, x)=\sum_{i=1}^{n} \frac{\partial M(q)}{\partial q_{i}} x_{i}
$$

Proof: It is known that $\frac{\partial \mathrm{M}_{\mathrm{i}}}{\partial \mathrm{q}} \mathrm{xe}_{\mathrm{i}}^{\mathrm{T}}=\sum_{\mathrm{j}=1}^{\mathrm{n}} \frac{\partial \mathrm{M}_{\mathrm{i}}}{\partial \mathrm{q}_{\mathrm{j}}} \mathrm{x}_{\mathrm{j}} \mathrm{e}_{\mathrm{i}}^{\mathrm{T}}$ and using the definition 2 the property is proved as follows

$$
M_{v}(q, x)=\sum_{i=1}^{n} \sum_{j=1}^{n} \frac{\partial M_{i}}{\partial q_{j}} x_{j} e_{i}^{T}=\sum_{j=1}^{n}\left(\sum_{i=1}^{n} \frac{\partial M_{i}}{\partial q_{j}} e_{i}^{T}\right) x_{j}=\sum_{j=1}^{n} \frac{\partial M(q)}{\partial q_{j}} x_{j}
$$

Q.E.D.

\subsection{Properties of the fundamental matrices}

Subsequently, some properties related to the fundamental matrices are analyzed. Following a systematic methodology, the properties have been classified into two groups: commutation properties and representation properties.

\subsubsection{Commutation properties}

Commutation properties permit interchange of an external arbitrary vector $\mathrm{y}$ and a vector $\mathrm{x}$ passed to a fundamental matrix as an argument. The following property makes possible the commutation while keeping the type of the fundamental matrices. This means that the transpose of the inertia derivative matrix can be transformed into the same structure by simply interchanging the roles of $\mathrm{x}$ and $\mathrm{y}$.

Property 3: $M_{D}^{T}(q, x) y=M_{D}^{T}(q, y) x$

The proof of the last property follows directly from the definition of $M_{D}$. The following property allows to pass from a type of fundamental matrix to another commuting the vectors $\mathrm{x}$ and $\mathrm{y}$.

Property 4: $M_{v}(q, x) y=M_{D}(q, y) x$

Proof :

Q.E.D.

$$
M_{v}(q, x) y=\sum_{i=1}^{n} \frac{\partial M_{i}}{\partial q} x e_{i}^{T} y=\sum_{i=1}^{n} \frac{\partial M_{i}}{\partial q} x_{i}=M_{D}(q, y) x
$$

\subsubsection{Properties of representation of the Coriolis/centripetal matrix}

These properties are very important to describe the Coriolis/centripetal matrix from the fundamental structures. 
Property 5:

$$
\mathbf{M}_{\mathrm{D}}^{\mathrm{T}}(\mathrm{q}, \dot{\mathrm{q}})=\sum_{\mathrm{i}=1}^{\mathrm{n}} \frac{\partial \mathrm{M}_{\mathrm{i}}^{\mathrm{T}}}{\partial \mathrm{q}} \dot{\mathrm{q}} \mathrm{e}_{\mathrm{i}}^{\mathrm{T}}
$$

Proof: First of all, the transpose of the inertia derivative matrix can be represented as $M_{D}^{T}(q, \dot{q})=\sum_{j=1}^{n} e_{j} \dot{q}^{T} \sum_{i=1}^{n} \frac{\partial M_{i}}{\partial q_{j}} e_{i}^{T}$ using the definition 1 and the fact that the differentiation of the inertia matrix with respect to the generalized coordinate $q_{j}$ is $\frac{\partial M(q)}{\partial q_{j}}=\sum_{i=1}^{n} \frac{\partial M_{i}}{\partial q_{j}} e_{i}^{T}$. Since scalar product is commutative the following expression is derived, $\dot{\mathrm{q}}^{\mathrm{T}} \frac{\partial \mathrm{M}_{\mathrm{i}}}{\partial \mathrm{q}_{\mathrm{j}}}=\frac{\partial \mathrm{M}_{\mathrm{i}}^{\mathrm{T}}}{\partial \mathrm{q}_{\mathrm{j}}} \dot{\mathrm{q}}$, and as a result $M_{D}^{T}(q, \dot{q})=\sum_{j=1}^{n} e_{j} \sum_{i=1}^{n} \frac{\partial M_{i}^{T}}{\partial q_{j}} \dot{q} e_{i}^{T}$. The order of summation is needed to be permutated to get the proposed identity.

$$
\mathrm{M}_{\mathrm{D}}^{\mathrm{T}}(\mathrm{q}, \dot{\mathrm{q}})=\sum_{\mathrm{i}=1}^{\mathrm{n}} \sum_{\mathrm{j}=1}^{\mathrm{n}}\left(\frac{\partial \mathrm{M}_{\mathrm{i}}}{\partial \mathrm{q}_{\mathrm{j}}} \mathrm{e}_{j}^{\mathrm{T}}\right)^{\mathrm{T}} \dot{\mathrm{q}} \mathrm{e}_{\mathrm{i}}^{\mathrm{T}}=\sum_{\mathrm{i}=1}^{\mathrm{n}} \frac{\partial \mathrm{M}_{\mathrm{i}}^{\mathrm{T}}}{\partial \mathrm{q}} \dot{\mathrm{q}} \mathrm{e}_{\mathrm{i}}^{\mathrm{T}}
$$

Q.E.D.

Below, some representations of the Coriolis/centripetal matrix are introduced as properties derived from $M_{D}$ and $M_{v}$.

Property 6: The matrix of Coriolis/centripetal effects can be expressed as

$$
C(q, \dot{\mathrm{q}})=\frac{1}{2}\left(\mathrm{M}_{\mathrm{v}}(\mathrm{q}, \dot{\mathrm{q}})+\mathrm{M}_{\mathrm{D}}(\mathrm{q}, \dot{\mathrm{q}})-\mathrm{M}_{\mathrm{D}}^{\mathrm{T}}(\mathrm{q}, \dot{\mathrm{q}})\right)=\frac{1}{2}\left(\mathrm{M}_{\mathrm{v}}(\mathrm{q}, \dot{\mathrm{q}})+\mathrm{J}(\mathrm{q}, \dot{\mathrm{q}})\right)
$$

where $J(q, \dot{q})=M_{D}(q, \dot{q})-M_{D}^{T}(q, \dot{q})$ is a skew symmetric matrix, i.e. $J(q, \dot{q})=-J^{T}(q, \dot{q})$.

Proof: This is an immediate consequence of the representation of $C(q, \dot{q})$ by means of the property 1 and the fact that the inertia velocity matrix is $M_{v}(q, \dot{q})=\dot{M}(q)$.

In a general way, the following representation can be derived

$$
C(q, x)=\frac{1}{2}\left(M_{v}(q, x)+J(q, x)\right)
$$

where $x$ is a vector of dimension $n$ and $J(q, x)=M_{D}(q, x)-M_{D}^{T}(q, x)$ is a skew symmetric matrix. It is remarkable that the definition of the Coriolis/centripetal matrix presented above, is different from the definition given by (Wen,1988) in the identity 2, $C(q, z) z=\frac{1}{2}\left(M_{D}(q, z)-J(q, z) z\right)$. An interesting property which is a direct implication of the property 4 is that, by setting $x=y$ in $C(q, x) y$.

Property 7: The Coriolis/centripetal force can be represented as

$$
C(\mathrm{q}, \dot{\mathrm{q}}) \dot{\mathrm{q}}=\left(\dot{\mathrm{M}}(\mathrm{q})-\frac{1}{2} \mathrm{M}_{\mathrm{D}}^{\mathrm{T}}(\mathrm{q}, \dot{\mathrm{q}})\right) \dot{\mathrm{q}}
$$

or in a general form as 


$$
C(q, x) x=M_{v}(q, x) x-\frac{1}{2} M_{D}^{T}(q, x) x
$$

where $x$ is an arbitrary vector of dimension $n$ :

Property 8: The Coriolis/centripetal matrix commutes with external vectors

$$
C(q, x) y=C(q, y) x
$$

Proof: In order to see this point the representation of the Coriolis/centripetal matrix will be used as a sum of the inertia velocity matrix, $M_{v}(q, x)$ and the skew symmetric matrix $\mathrm{J}(\mathrm{q}, \mathrm{x})$ given by equation (12).

$$
C(q, x) y=\frac{1}{2}\left(M_{v}(q, x) y+J(q, x) y\right)
$$

On one hand, it is known that $J(q, x)=M_{D}(q, x)-M_{D}^{T}(q, x)$. Using the commutation properties 2 and 3 the following expression is derived

$$
C(q, x) y=\frac{1}{2}\left(M_{D}(q, y) x-M_{D}^{T}(q, y) x+M_{D}(q, x) y\right)
$$

On other hand, $J(q, y) x=M_{D}(q, y) x-M_{D}^{T}(q, y) x$ and then applying the commutation property 3 to $M_{D}(q, x) y$ the following result is achieved as claimed

$$
C(q, x) y=\frac{1}{2}\left(J(q, y) x+M_{v}(q, y) x\right)=C(q, y) x
$$

Q.E.D

\section{Design of Emulators for Robot Manipulators.}

\subsection{Functional and Linear Parameterization.}

The approach that follows is founded on the idea to find an emulator as a function close to the non-linear terms involved in the dynamics equations of a robot manipulator. In order to get a model from a practical point of view, uncertainties in the nonlinear terms. getting arise from the partial information about the exact structure of the dynamics, must be taken into account. The inaccuracies of a model can be classified into two classes: structured and unstructured uncertainties. The first kind of uncertainties comes out from the inaccuracies of the parameters whereas the unstructured uncertainties are related to unmodeled dynamics, see (Slotine \& Li,1991). Thus, the uncertainties can be adaptatively compensated by defining each coefficient as a separate parameter so that the dynamics can be expressed in the linear in the parameters (LIP) and this means that nonlinearities can be split up into an unknown vector of physical parameters $P$ and a known matrix of basis nonlinear functions $\Psi(\mathrm{q}, \dot{\mathrm{q}}, \mathrm{x}, \mathrm{y})$ comprising the elements of $\mathrm{M}(\mathrm{q}), \mathrm{C}(\mathrm{q}, \dot{\mathrm{q}}), \mathrm{G}(\mathrm{q})$ and $\mathrm{F}(\mathrm{q}, \dot{\mathrm{q}})$, referred to as 
regression matrix. Therefore, the nonlinear function $f(x)$ can be written in this sense adding a term of error $\varepsilon$, see (Ge et al., 1998).

$$
f(q, \dot{q}, x, y)=\Psi(q, \dot{q}, x, y) P+\varepsilon
$$

The linearity of the parameters is the major structural property of robot manipulators and has been analyzed in (Lewis et al., 2003). This linear factorization is always possible to be done for the rigid body dynamics of a fixed-based manipulator as long as the physical uncertainty is on the mass properties of the robot links. Furthermore, linearity of the parameters is the first assumption in the most of adaptive controllers. An alternative representation of the nonlinear component is as follows

$$
\mathrm{f}(\mathrm{q}, \dot{\mathrm{q}}, \mathrm{x}, \mathrm{y})=\mathrm{R}(\mathrm{q}, \dot{\mathrm{q}}) \mathrm{v}(\mathrm{x}, \mathrm{y})
$$

where $\mathrm{R}(\mathrm{q}, \dot{\mathrm{q}})=(\mathrm{M}(\mathrm{q}) \quad \mathrm{C}(\mathrm{q}, \dot{\mathrm{q}}) \quad \mathrm{G}(\mathrm{q})) \in \mathbb{R}^{\mathrm{n} \times(2 \mathrm{n}+1)} \quad$ and $\quad \mathrm{v}=\left(\mathrm{y}^{\mathrm{T}} \quad \mathrm{x}^{\mathrm{T}} \quad 1\right) \in \mathbb{R}^{2 \mathrm{n}+1}$. This factorization is always attainable whereas the linearity in the parameters (LIP) is only obtained under some circumstances. In the literature, emulators based on regression matrices have been used to approximate the nonlinear dynamics as a whole, as follows

$$
\mathcal{N}(\mathrm{q}, \dot{\mathrm{q}}, \ddot{\mathrm{q}})=\mathrm{M}(\mathrm{q}) \ddot{\mathrm{q}}+\mathrm{C}(\mathrm{q}, \dot{\mathrm{q}}) \dot{\mathrm{q}}+\mathrm{G}(\mathrm{q})
$$

As an attempt to obtain more efficient computation, the emulator approximating the nonlinearity $f(x)$ is split up into several smaller components:

$$
\mathrm{f}(\mathrm{q}, \dot{\mathrm{q}}, \mathrm{x}, \mathrm{y})=\mathrm{f}_{\mathrm{m}}(\mathrm{q}, \mathrm{y})+\mathrm{f}_{\mathrm{c}}(\mathrm{q}, \dot{\mathrm{q}}, \mathrm{x})+\mathrm{f}_{\mathrm{g}}(\mathrm{q})+\mathrm{f}_{\mathrm{f}}(\mathrm{q}, \dot{\mathrm{q}})
$$

The function $f_{m}(q, x)=M(q) y$, stands for the nonlinearity of inertial terms and can be written taking into account that the components of $\mathrm{M}(\mathrm{q})$ are continuous functions of their arguments so that each component can be uniformly approximated on any compact subset of the state space by an appropriately designed emulator.

From now on we assume that the number of parameters to approximate the column $\mathrm{i}$ of a matrix is $1_{i}$.

\subsection{Inertia matrix $\mathbf{M}(\mathbf{q})$.}

\subsubsection{Ideal Case}

The inertia matrix $M(q)$ consists of column vectors $M_{i}(q)$ that can be approximated by regression matrices

$$
\mathrm{M}_{\mathrm{i}}(\mathrm{q})=\Psi_{\mathrm{m}_{\mathrm{i}}}(\mathrm{q}) \xi_{\mathrm{m}_{\mathrm{i}}}
$$


where $\Psi_{\mathrm{m}_{\mathrm{i}}}(\mathrm{q}) \in \mathcal{M}_{\mathrm{n} \times \mathrm{l}_{\mathrm{i}}}(\mathbb{R})$ is a regression matrix of known robot functions and $\xi_{\mathrm{m}_{\mathrm{i}}} \in \mathbb{R}^{1_{i}}$ is a vector of unknown parameters (e.g. masses, inertia moments and link parameters). Then, with an arbitrary vector $x \in \mathbb{R}^{\mathrm{n}}$, there follows the decomposition

$$
M(q) x=\sum_{i=1}^{n} M_{i}(q) x_{i}=\left(\sum_{i=1}^{n} \Psi_{m_{i}}(q) x_{i} \xi_{m_{i}}\right)
$$

On the assumption that the same regression matrix serves for each column, i.e. $\Psi_{\mathrm{m}_{1}}(\mathrm{q})=\Psi_{\mathrm{m}_{2}}(\mathrm{q})=\cdots \Psi_{\mathrm{m}_{\mathrm{n}}}(\mathrm{q})=\Psi_{\mathrm{m}}(\mathrm{q}) \in \mathcal{M}_{\mathrm{n} \times \mathrm{l}}(\mathbb{R})$, one may rewrite equation (24) by resorting to the Kronecker product as

$$
\mathrm{M}(\mathrm{q}) \mathrm{x}=\Phi_{\mathrm{m}}(\mathrm{q}, \mathrm{x}) \xi_{\mathrm{m}}
$$

where $\quad \xi_{\mathrm{m}} \in \mathbb{R}^{1}$ is an 1-dimensional vector of parameters and $\Phi_{\mathrm{m}}(\mathrm{q}, \mathrm{x})=\left(\mathrm{x}^{\mathrm{T}} \otimes \Psi_{\mathrm{m}}(\mathrm{q})\right) \in \mathcal{M}_{\mathrm{n} \times \mathrm{l}}(\mathbb{R})$ is the regression matrix of the generalized inertia matrix.

\subsubsection{Real Case}

Given a closed, bounded subset $\Omega \subseteq \mathbb{R}^{\mathrm{n}}$, and a specified accuracy $\varepsilon_{\mathrm{m}_{\mathrm{i}}}$, there exist values for the design parameters $1_{i}$ and $\xi_{m_{i}}$ so that for all $q(t) \in \Omega$ the following inequality is satisfied:

$$
\left\|\mathrm{M}_{\mathrm{i}}(\mathrm{q})-\Psi_{\mathrm{m}_{\mathrm{i}}}(\mathrm{q}) \xi_{\mathrm{m}_{\mathrm{i}}}\right\| \leq \varepsilon_{\mathrm{m}_{\mathrm{i}}}
$$

For the sake of simplicity, we have assumed that $\Psi_{m_{i}}(q)$ are equal for all $i=1, \ldots, n$. The inertia matrix consists of column vectors that can be approximated as

$$
M(q)=\sum_{i=1}^{n} M_{i}(q) e_{i}^{T}=\left(\sum_{i=1}^{n} \Psi_{m_{i}}(q) \xi_{m_{i}} e_{i}^{T}\right)+\varepsilon_{m}(q)
$$

where $\varepsilon_{\mathrm{m}}(\mathrm{q}) \in \mathbb{R}^{\mathrm{n} \times \mathrm{n}}$ is the functional reconstruction error.

It is convenient to underline that the vector function $\Phi_{\mathrm{m}}(\mathrm{q}, \mathrm{x})$ only can be expressed by the Kronecker product whenever the hypothesis $\Phi_{\mathrm{m}}(\mathrm{q}, \mathrm{x})=\Psi_{\mathrm{m}_{\mathrm{i}}}(\mathrm{q})=\Psi_{\mathrm{m}}(\mathrm{q})$ holds for all $\mathrm{i}=1, \ldots, \mathrm{n}$. As a consequence, a linear transformation with a change of basis can be derived in terms of the Kronecker product

$$
\mathrm{M}(\mathrm{q}) \mathrm{x}=\Phi_{\mathrm{m}}(\mathrm{q}, \mathrm{x}) \xi_{\mathrm{m}}+\mathrm{E}_{\mathrm{m}}(\mathrm{q}, \mathrm{x})
$$


The expansion given by (28) actually approximates the linear transformation $M(q) x$ to a certain degree of accuracy $E_{m}(q, x)=\varepsilon_{m} x$ by using an emulator with the position joint vector as the input. Specifically, the emulator in $(28)$ has the vector $\left(\mathrm{q}^{\mathrm{T}}, \mathrm{x}^{\mathrm{T}}\right)^{\mathrm{T}}$ as its input and $\mathrm{n}$ outputs, and a collection of simple computing elements $\Phi_{\mathrm{m}}(\mathrm{q}, \mathrm{x})$ are used to approximate the function $\mathrm{f}_{\mathrm{m}}(\mathrm{q}, \mathrm{x})$.

\subsection{Fundamental matrices.}

For the sake of simplicity in the following, the matrix derivative of $\Psi_{m}(q)$ with $q \in \mathbb{R}^{n}$ will be denoted as

$$
\frac{\partial \Psi_{\mathrm{m}}(\mathrm{q})}{\partial \mathrm{q}} \triangleq\left(\begin{array}{c}
\frac{\partial \Psi_{\mathrm{m}}(\mathrm{q})}{\partial \mathrm{q}_{1}} \\
\cdots \\
\frac{\partial \Psi_{\mathrm{m}}(\mathrm{q})}{\partial \mathrm{q}_{\mathrm{n}}}
\end{array}\right) \in \mathcal{M}_{\mathrm{n}^{2} \times 1}(\mathbb{R})
$$

\subsubsection{Inertia Derivative Matrix $\mathrm{M}_{\mathrm{D}}(\mathrm{q}, \mathrm{x})$}

\subsubsection{Real Case}

It is possible to express the inertia derivative matrix as consisting of two terms, the approximation component $\hat{M}_{D}(q, x)$ and the reconstruction error $E_{D}(q, x)$.

$$
M_{D}(q, x)=\sum_{j=1}^{n} \frac{\partial \hat{M}(q)}{\partial q_{j}} x_{j}^{T}+\sum_{j=1}^{n} \frac{\partial E_{m}(q, x)}{\partial q_{j}} e_{j}^{T}
$$

Following the discussion given in the ideal case, the approximation term $\hat{M}_{D}(q, x) y$ can be expressed in the regression form:

$$
\hat{\mathrm{M}}_{\mathrm{D}}(\mathrm{q}, \mathrm{x}) \mathrm{y}=\Phi_{\mathrm{D}}(\mathrm{q}, \mathrm{x}, \mathrm{y}) \xi_{\mathrm{m}}
$$

\subsubsection{Ideal Case}

The following lemmas are helpful for characterizing the inertia derivative matrix in LIP form.

Lemma 1 (LIP form of $\mathbf{M}_{\mathbf{D}}$ ). For arbitrary vectors $x, y \in \mathbb{R}^{n}, q \in \Omega_{q} \subseteq \mathbb{R}^{n}$, the inertia derivative matrix can be written in the LIP form as follows

$$
\mathrm{M}_{\mathrm{D}}(\mathrm{q}, \mathrm{x}) \mathrm{y}=\Phi_{\mathrm{D}}(\mathrm{q}, \mathrm{x}, \mathrm{y}) \xi_{\mathrm{m}}
$$

where $\xi_{\mathrm{m}} \in \mathbb{R}^{1}$ is the parameter vector of the generalized inertia matrix and 
$\Phi_{\mathrm{D}} \in \mathcal{M}_{\mathrm{n} \times 1}(\mathbb{R})$ a regression matrix:

$$
\begin{aligned}
\Phi_{\mathrm{D}}(\mathrm{q}, \mathrm{x}, \mathrm{y}) & =\left(\mathrm{y}^{\mathrm{T}} \otimes \mathrm{I}_{\mathrm{n}}\right) \Psi(\mathrm{q}, \mathrm{x}) \\
\Psi(\mathrm{q}, \mathrm{x}) & =\left(\mathrm{x}^{\mathrm{T}} \otimes \frac{\partial \Psi_{\mathrm{m}}(\mathrm{q})}{\partial \mathrm{q}}\right)
\end{aligned}
$$

Proof: This fact can be straightforward proved by resorting to the definition of $M_{D}$ given above:

$$
\mathrm{M}_{\mathrm{D}}(\mathrm{q}, \mathrm{x}) \mathrm{y}=\sum_{\mathrm{i}=1}^{\mathrm{n}} \frac{\partial \mathrm{M}(\mathrm{q})}{\partial \mathrm{q}_{\mathrm{i}}} \mathrm{xy}_{\mathrm{i}}=\left(\sum_{\mathrm{i}=1}^{\mathrm{n}} \frac{\partial \Phi_{\mathrm{m}}(\mathrm{q}, \mathrm{x})}{\partial \mathrm{q}_{\mathrm{i}}} \mathrm{y}_{\mathrm{i}}\right) \xi_{\mathrm{m}}=\left(\mathrm{x}^{\mathrm{T}} \otimes \sum_{\mathrm{i}=1}^{\mathrm{n}} \frac{\partial \Psi_{\mathrm{m}}(\mathrm{q})}{\partial \mathrm{q}_{\mathrm{i}}} \mathrm{y}_{\mathrm{i}}\right) \xi_{\mathrm{m}}=\Phi_{\mathrm{D}}(\mathrm{q}, \mathrm{x}, \mathrm{y}) \xi_{\mathrm{m}}
$$

By closely examining the structure of $\Phi_{\mathrm{D}}$ and using the property

$$
\sum_{i=1}^{n} \frac{\partial \Psi_{m}(q)}{\partial q_{i}} y_{i}=\left(y^{T} \otimes I_{n}\right) \frac{\partial \Psi_{m}(q)}{\partial q}
$$

it is easy to conclude that

$$
\begin{aligned}
\Phi_{\mathrm{D}}(\mathrm{q}, \mathrm{x}, \mathrm{y}) & =\mathrm{x}^{\mathrm{T}} \otimes\left(\left(\mathrm{y}^{\mathrm{T}} \otimes \mathrm{I}_{\mathrm{n}}\right) \frac{\partial \Psi_{\mathrm{m}}(\mathrm{q})}{\partial \mathrm{q}}\right)=\left[\mathrm{x} \otimes\left(\frac{\partial \Psi_{\mathrm{m}}^{\mathrm{T}}(\mathrm{q})}{\partial \mathrm{q}}\left(\mathrm{y} \otimes \mathrm{I}_{\mathrm{n}}\right)\right]^{\mathrm{T}}=\right. \\
& =\left[\left(\mathrm{x} \otimes \frac{\partial \Psi_{\mathrm{m}}^{\mathrm{T}}(\mathrm{q})}{\partial \mathrm{q}}\right)\left(\mathrm{y} \otimes \mathrm{I}_{\mathrm{n}}\right)\right]^{\mathrm{T}}=\left(\mathrm{y}^{\mathrm{T}} \otimes \mathrm{I}_{\mathrm{n}}\right) \Psi(\mathrm{q}, \mathrm{x})
\end{aligned}
$$

\subsubsection{Fundamental Matrix $\mathrm{M}_{\mathrm{v}}(\mathrm{q}, \mathrm{x})$}

\subsubsection{Ideal Case}

Lemma 2. For arbitrary vectors $\mathrm{x}, \mathrm{y} \in \mathbb{R}^{\mathrm{n}}, \mathrm{q} \in \Omega_{\mathrm{q}} \subseteq \mathbb{R}^{\mathrm{n}}$, the inertia velocity matrix can be written as

$$
\mathrm{M}_{\mathrm{v}}(\mathrm{q}, \mathrm{x}) \mathrm{y}=\Phi_{\mathrm{v}}(\mathrm{q}, \mathrm{x}, \mathrm{y}) \xi_{\mathrm{m}}
$$

where $\Phi_{\mathrm{v}}(\mathrm{q}, \mathrm{x}, \mathrm{y})=\sum_{\mathrm{i}=1}^{\mathrm{n}} \frac{\partial \Phi_{\mathrm{m}}(\mathrm{q}, \mathrm{y})}{\partial \mathrm{q}_{\mathrm{i}}} \mathrm{x}_{\mathrm{i}}$.

Proof: Owing to the commutation property of fundamental matrices the result is direct.

Remark: It is easy to show that the Jacobian matrix $\Phi_{\mathrm{v}}(\mathrm{q}, \mathrm{x}, \mathrm{y})$ also satisfies the commutation property, $\Phi_{\mathrm{v}}(\mathrm{q}, \mathrm{x}, \mathrm{y})=\Phi_{\mathrm{D}}(\mathrm{q}, \mathrm{y}, \mathrm{x})$.This is an immediate consequence of the commutation property of $\mathrm{M}_{\mathrm{v}}(\mathrm{q}, \mathrm{y})$ and $\mathrm{M}_{\mathrm{D}}(\mathrm{q}, \mathrm{x})$ as given in the identity 3 . 


\subsubsection{Real Case}

The inertia velocity matrix $\mathrm{M}_{\mathrm{v}}(\mathrm{q}, \mathrm{x})$ can be seen as consisting of an approximation term $\hat{M}_{v}(q, x)$ and a reconstruction error $E_{v}(q, x)$. The approximation term $\hat{M}_{v}(q, x)$ can be written in terms of the Jacobian of $\Phi_{\mathrm{v}}(\mathrm{q}, \mathrm{x}, \mathrm{y})$ as

$$
\hat{M}_{v}(q, x) y=\Phi_{v}(q, x, y) \xi_{m}
$$

and the error $E_{v}(q, x)$ is derived from the gradient of the inertia error $\varepsilon_{m}(q)$.

$$
E_{v}(q, x)=\sum_{i=1}^{n} \frac{\partial \varepsilon_{m}}{\partial q_{i}} x_{i}=\sum_{i=1}^{n} \frac{\partial \varepsilon_{m}(q)}{\partial q_{i}} x_{i}
$$

\subsubsection{Transpose of the Inertia Derivative Matrix}

Now that it is known how $M_{D}$ can be written in LIP form, the main challenge, now, is to extend this result to its transpose. This is more difficult since involves a permutation matrix as stated in the following lemma.

Lemma 3: Let $\mathrm{x}, \mathrm{y} \in \mathbb{R}^{\mathrm{n}}, \mathrm{q} \in \Omega_{\mathrm{q}} \subseteq \mathbb{R}^{\mathrm{n}}$ arbitrary vectors with appropriate units and $\mathrm{P}$ a permutation matrix 1 defined as follows

$$
P(n, m)=\sum_{i=1}^{n} \sum_{j=1}^{n} E_{i j} \otimes E_{j i}
$$

where $E_{i j}=e_{i} e_{j}^{T}$ is a unit matrix having 1 in position $(i, j)$ and all other entries are zero. Under these conditions, the term $M_{D}^{T}(q, x)$ can be written in LIP form as follows

$$
M_{D}^{T}(q, x) y=\left(x^{T} \otimes I_{n}\right) P(n, n) \psi(q, y) \xi_{m}
$$

Proof: By virtue of definition 1 and lemma 1, the generalized force $M_{D}^{T}(q, x) y$ can be directly derived in the LIP form which can be detailed into

$$
\begin{aligned}
M_{D}^{T}(q, x) y & =\sum_{i=1}^{n} e_{i}\left(x^{T} \frac{\partial M(q)}{\partial q_{i}} y\right)=\left(I_{n} \otimes x^{T}\right) \frac{\partial M(q)}{\partial q} y= \\
& =\left(I_{n} \otimes x^{T}\right) \frac{\partial \Phi_{m}(q, y)}{\partial q} \xi_{m}=\left(I_{n} \otimes x^{T}\right)\left(y^{T} \otimes \frac{\partial \Psi_{m}(q)}{\partial q}\right) \xi_{m}
\end{aligned}
$$

$1 \mathrm{P}(\mathrm{m}, \mathrm{n})$ is a matrix of zeroes and ones for which $\mathrm{P}(\mathrm{m}, \mathrm{n})^{-1}=\mathrm{P}(\mathrm{m}, \mathrm{n})^{\mathrm{T}}=\mathrm{P}(\mathrm{m}, \mathrm{n})$. 
With reference to the property $\mathrm{B} \otimes \mathrm{A}=\mathrm{P}(\mathrm{m}, \mathrm{p})^{\mathrm{T}}(\mathrm{A} \otimes \mathrm{B}) \mathrm{P}(\mathrm{n}, \mathrm{q})$ for all $\mathrm{A} \in \mathcal{M}_{\mathrm{m} \times \mathrm{n}}(\mathbb{R})$ and $\mathrm{B} \in \mathcal{M}_{\mathrm{p} \times \mathrm{q}}(\mathbb{R})$, (see Corollary 4.3.10., p. 260, in (Horn \& Johnson,1999)), the term $\left(\mathrm{x}^{\mathrm{T}} \otimes \mathrm{I}_{\mathrm{n}}\right)$ can be commutated as

$$
\left(x^{T} \otimes I_{n}\right)=P(n, 1)^{T}\left(I_{n} \otimes x^{T}\right) P(n, n)
$$

The last identity can be simplified further by exploiting the structure of the permutation matrices. In particular, it is easy to show that $P(n, 1)=P(1, n)=I_{n}$ (see problem 18, section 4.3 , p. 265, in (Horn \& Johnson, 1999)), which leads to

$$
\left(I_{n} \otimes x^{T}\right)=\left(x^{T} \otimes I_{n}\right) P(n, n)
$$

Therefore,

$$
\begin{aligned}
M_{D}^{T}(q, x) y & =\left(x^{T} \otimes I_{n}\right) P(n, n)\left(y^{T} \otimes \frac{\partial \Psi_{m}(q)}{\partial q}\right) \xi_{m}= \\
& =\left(x^{T} \otimes I_{n}\right) P(n, n) \Psi(q, y) \xi_{m}
\end{aligned}
$$

Remark: The permutation matrix in the last lemma can be also written as

$$
\mathrm{P}(\mathrm{n}, \mathrm{n})=\sum_{\mathrm{i}=1}^{\mathrm{n}} \mathrm{e}_{\mathrm{i}} \otimes \mathrm{I}_{\mathrm{n}} \otimes \mathrm{e}_{\mathrm{i}}^{\mathrm{T}}=\sum_{\mathrm{i}=1}^{\mathrm{n}} \mathrm{e}_{\mathrm{i}}^{\mathrm{T}} \otimes \mathrm{I}_{\mathrm{n}} \otimes \mathrm{e}_{\mathrm{i}}
$$

For more details the reader is referred to the problem 21, section 4.3. p.286,in (Horn \& Johnson, 1999).

\subsubsection{Coriolis/Centripetal Matrix}

On the basis of the description of $M_{D}$ and $M_{D}^{T}$ in LIP form, the skew-symmetric matrix J can be also represented as LIP.

Lemma 4: Let $\mathrm{x}, \mathrm{y} \in \mathbb{R}^{\mathrm{n}}, \mathrm{q} \in \Omega_{\mathrm{q}} \subseteq \mathbb{R}^{\mathrm{n}}$ arbitrary vectors with appropriate units. The skewsymmetric matrix $J(q, x)$ can be expressed is linear in the parameters,

$J(q, x) y=\Phi_{J}(q, x, y) \xi_{m}$

where $\Phi_{J}(q, x, y)=\left(y^{T} \otimes I_{n}\right)\left(I_{n^{2}}-P(n, n)\right) \psi(q, x)$.

Proof: It is straightforward that

$J(q, x) y=M_{D}(q, x) y-M_{D}^{T}(q, x) y=\left(y^{T} \otimes I_{n}\right)\left(I_{n^{2}}-P(n, n)\right) \psi(q, x) \xi_{m}$

Lemma 5: For arbitrary vectors $\mathrm{x}, \mathrm{y} \in \mathbb{R}^{\mathrm{n}}, \mathrm{q} \in \Omega_{\mathrm{q}} \subseteq \mathbb{R}^{\mathrm{n}}$, the inertia velocity matrix can be written as

$\mathrm{M}_{\mathrm{v}}(\mathrm{q}, \mathrm{x}) \mathrm{y}=\Phi_{\mathrm{v}}(\mathrm{q}, \mathrm{x}, \mathrm{y}) \xi_{\mathrm{m}}$ 
where $\Phi_{\mathrm{v}}(\mathrm{q}, \mathrm{x}, \mathrm{y})=\sum_{\mathrm{i}=1}^{\mathrm{n}} \frac{\partial \Phi_{\mathrm{m}}(\mathrm{q}, \mathrm{y})}{\partial \mathrm{q}_{\mathrm{i}}} \mathbf{x}_{\mathrm{i}}$.

Proof: This is direct.

Remark: It is observed the following identity: $\Phi_{\mathrm{D}}(\mathrm{q}, \mathrm{x}, \mathrm{y})=\Phi_{\mathrm{v}}(\mathrm{q}, \mathrm{y}, \mathrm{x})$, which is consistent with the commutation property.

Remark: An alternative way for J is obtained by resorting to the commutation property:

$$
\begin{aligned}
M_{v}(q, x) y-M_{D}^{T}(q, x) y & =M_{D}(q, y) x-M_{D}^{T}(q, y) x= \\
& =\left(x^{T} \otimes I_{n}\right)\left(I_{n^{2}}-P(n, n)\right) \psi(q, y) \xi_{m}=J(q, y) x
\end{aligned}
$$

Remarkably, the above lemmas can be conveniently used to write the Coriolis/centripetal matrix in LIP form.

Proposition 1 (Coriolis/Centripetal matrix in LIP form): Let $x, y \in \mathbb{R}^{n}, q \in \Omega_{q} \subseteq \mathbb{R}^{n}$ arbitrary vectors, the Coriolis/centripetal effect $C(q, x) y$ can be linearly factorized as a regression matrix $\Phi_{\mathrm{C}}(\mathrm{q}, \mathrm{x}, \mathrm{y})$ and a parameter vector $\xi_{\mathrm{m}}$, i.e. $\mathrm{C}(\mathrm{q}, \mathrm{x}) \mathrm{y}=\Phi_{\mathrm{C}}(\mathrm{q}, \mathrm{x}, \mathrm{y}) \xi_{\mathrm{m}}$, where $\Phi_{C}$ is given by

$\Phi_{C}(\mathrm{q}, \mathrm{x}, \mathrm{y})=\frac{1}{2}\left[\left(\mathrm{x}^{\mathrm{T}} \otimes \mathrm{I}_{\mathrm{n}}\right) \psi(\mathrm{q}, \mathrm{y})+\left(\mathrm{y}^{\mathrm{T}} \otimes \mathrm{I}_{\mathrm{n}}\right)\left(\mathrm{I}_{\mathrm{n}^{2}}-\mathrm{P}(\mathrm{n}, \mathrm{n})\right) \psi(\mathrm{q}, \mathrm{x})\right]$

Proof: By restoring to the LIP form of $\mathrm{M}_{\mathrm{v}}$ and $\mathrm{J}$, matrix $\mathrm{C}$ can be written as

$$
\begin{aligned}
C(q, x) y & =\frac{1}{2}\left(M_{v}(q, x) y+J(q, x) y\right)= \\
& =\frac{1}{2}\left[\left(x^{T} \otimes I_{n}\right) \psi(q, y)+\left(y^{T} \otimes I_{n}\right)\left(I_{n^{2}}-P(n, n)\right) \psi(q, x)\right] \xi_{m}
\end{aligned}
$$

\subsection{Model Errors}

The dynamic model of the robot manipulator is allowed to be imprecise since the nonlinear function $\mathrm{f}(\mathrm{q}, \dot{\mathrm{q}}, \mathrm{x}, \mathrm{y})=\mathrm{M}(\mathrm{q}) \mathrm{x}+\mathrm{C}(\mathrm{q}, \dot{\mathrm{q}}) \mathrm{y}+\mathrm{G}(\mathrm{q})$, (where $\mathrm{x}, \mathrm{y} \in \mathbb{R}^{\mathrm{n}}$ are arbitrary vectors usually with units of acceleration and velocity respectively),is not exactly known. The imprecision comes from unstructured uncertainties, namely modeling errors caused by the truncation of the Gaussian expansion series. A detailed description of the approximation errors is demanding from a modeling viewpoint. To point out the fundamental aspects of error modeling, it is convenient to express the total error as composed by three terms, (Mulero-Martinez, 2007a),

$$
E=E_{m}(q, x)+E_{C}(q, \dot{q}, y)+E_{G}(q)
$$

By referring to the expression of the Coriolis/centripetal matrix in (Mulero-Martínez,2007a) from the fundamental matrices $M_{D}$ and $M_{V}$, the Coriolis/centripetal errors $E_{C}(q, \dot{q}, y)$ can be written as

$$
E_{C}(q, \dot{q}, y)=\frac{1}{2}\left(E_{D}(q, \dot{q})-E_{D}^{T}(q, \dot{q})+E_{V}(q, \dot{q})\right) y
$$


The error term $E_{D}(q, \dot{q})$ is the approximation error associated with the fundamental matrix $M_{D}(q, \dot{q})$ and $E_{V}(q, \dot{q})$ regards with the velocity matrix $M_{V}(q, \dot{q})$. For the sake of simplicity the gradient of the inertia error $\varepsilon_{\mathrm{m}}(\mathrm{q})$ will be denoted as

$$
\frac{\partial \varepsilon_{\mathrm{m}}}{\partial \mathrm{q}} \triangleq\left(\frac{\partial \varepsilon_{\mathrm{m}}}{\partial \mathrm{q}_{1}}, \ldots, \frac{\partial \varepsilon_{\mathrm{m}}}{\partial \mathrm{q}_{\mathrm{n}}}\right) \in \mathbb{R}^{\mathrm{n} \times \mathrm{n}^{2}}
$$

These errors can be expressed in terms of the gradient of the inertia error $\varepsilon_{m}(q)$ as follows

$$
\begin{aligned}
& \mathrm{E}_{\mathrm{D}}(\mathrm{q}, \dot{\mathrm{q}})=\sum_{\mathrm{i}=1}^{\mathrm{n}} \frac{\partial \varepsilon_{\mathrm{m}}(\mathrm{q})}{\partial \mathrm{q}_{\mathrm{i}}} \dot{\mathrm{q}}_{\mathrm{i}}^{\mathrm{T}} \\
& \mathrm{E}_{\mathrm{V}}(\mathrm{q}, \dot{\mathrm{q}})=\sum_{\mathrm{i}=1}^{\mathrm{n}} \frac{\partial \varepsilon_{\mathrm{m}}(\mathrm{q})}{\partial \mathrm{q}_{\mathrm{i}}} \dot{\mathrm{q}}_{\mathrm{i}}
\end{aligned}
$$

For the following derivation, it is worth rewriting the mathematical errors in a more suitable form using the Kronecker product. This is written down in the following properties.

Claim 3: The linear transformation $E_{D}(q, \dot{q}) \dot{q}_{r}$ can be formulated in terms of the Kronecker product as

$$
\mathrm{E}_{\mathrm{D}}(\mathrm{q}, \dot{\mathrm{q}}) \dot{\mathrm{q}}_{\mathrm{r}}=\frac{\partial \varepsilon_{\mathrm{m}}(\mathrm{q})}{\partial \mathrm{q}}\left(\dot{\mathrm{q}}_{\mathrm{r}} \otimes \dot{\mathrm{q}}\right)
$$

Proof: The proof is derived directly from the definition of $E_{D}(q, \dot{q})$

$$
\mathrm{E}_{\mathrm{D}}(\mathrm{q}, \dot{\mathrm{q}}) \dot{\mathrm{q}}_{\mathrm{r}}=\sum_{\mathrm{j}=1}^{\mathrm{n}} \frac{\partial \varepsilon_{\mathrm{m}}(\mathrm{q})}{\partial \mathrm{q}_{\mathrm{j}}} \dot{\mathrm{q}} \mathrm{e}_{\mathrm{j}}^{\mathrm{T}} \dot{\mathrm{q}}_{\mathrm{r}}=\sum_{\mathrm{j}=1}^{\mathrm{n}} \frac{\partial \varepsilon_{\mathrm{m}}(\mathrm{q})}{\partial \mathrm{q}_{\mathrm{j}}} \dot{\mathrm{q}}_{\mathrm{q}_{\mathrm{j}}}=\frac{\partial \varepsilon_{\mathrm{m}}(\mathrm{q})}{\partial \mathrm{q}}\left(\dot{\mathrm{q}}_{\mathrm{r}} \otimes \dot{\mathrm{q}}\right)
$$

Claim 4: The linear transformation $E_{V}(q, \dot{q}) \dot{q}_{r}$ is expressed in terms of the Kronecker product as

$$
\mathrm{E}_{\mathrm{V}}(\mathrm{q}, \dot{\mathrm{q}}) \dot{\mathrm{q}}_{\mathrm{r}}=\frac{\partial \varepsilon_{\mathrm{m}}(\mathrm{q})}{\partial \mathrm{q}}\left(\dot{\mathrm{q}} \otimes \dot{\mathrm{q}}_{\mathrm{r}}\right)
$$

Proof: This fact can be trivially proved from the definition in equation (47)

$$
\mathrm{E}_{\mathrm{V}}(\mathrm{q}, \dot{\mathrm{q}}) \dot{\mathrm{q}}_{\mathrm{r}}=\sum_{\mathrm{i}=1}^{\mathrm{n}} \frac{\partial \varepsilon_{\mathrm{m}}(\mathrm{q})}{\partial \mathrm{q}_{\mathrm{i}}} \dot{\mathrm{q}}_{\mathrm{i}} \dot{\mathrm{q}}_{\mathrm{r}}=\frac{\partial \varepsilon_{\mathrm{m}}(\mathrm{q})}{\partial \mathrm{q}}\left(\dot{\mathrm{q}} \otimes \dot{\mathrm{q}}_{\mathrm{r}}\right)
$$

Remark: Equations (48) and (49) are not the same since the Kronecker product is not commutative, i.e. $\left(\dot{\mathrm{q}}_{\mathrm{r}} \otimes \dot{\mathrm{q}}\right) \neq\left(\dot{\mathrm{q}} \otimes \dot{\mathrm{q}}_{\mathrm{r}}\right)$.

\section{Design of the Adaptive Controller.}

\subsection{Error Dynamic Equation}

In order to manage equilibrium points at the origin, it is necessary to make a coordinate 
transformation so that a position error variable is considered, $e(t)=q_{d}(t)-q(t)$. Thus, convergene of trajectory $q(t)$ to the desired trajectory $q_{d}(t)$ can be analysed observing position error trajectories $\mathrm{e}(\mathrm{t})$ close to the origin in the phase space. The objective of the controller is both the stable tracking of trajectories and the rejection of disturbances. A good tracking performance means that the error converge to zero (asymptotic stability) or to a finite value, $\lim _{\mathrm{t} \rightarrow \infty} \mathrm{e}(\mathrm{t})=\mathrm{E}<\infty$. This idea is also applied to $\dot{\mathrm{q}}(\mathrm{t})$ and $\ddot{\mathrm{q}}(\mathrm{t})$ because a position trajectory is given by three quantities $(\mathrm{q}(\mathrm{t}), \dot{\mathrm{q}}(\mathrm{t}), \ddot{\mathrm{q}}(\mathrm{t}))$. Measurements of velocities are easy to get by tachometers, but sensors of acceleration are noisy and are not used for implementation in robotics field. This fact conjures up to use a filtered error signal, $r(t)$, that is a derivative filter or PD (Slotine \& Li, 1991):

$$
\mathrm{r}(\mathrm{t})=\dot{\mathrm{q}}_{\mathrm{r}}(\mathrm{t})-\dot{\mathrm{q}}(\mathrm{t})
$$

From (50) it is shown that $r(t)$ is a measurement of error between real velocity $\dot{q}(t)$ and reference velocity $\dot{\mathrm{q}}_{\mathrm{r}}(\mathrm{t})$. This reference velocity must not be confused with the desired velocity $\dot{\mathrm{q}}_{\mathrm{d}}(\mathrm{t})$. In fact, reference velocity is defined as follows

$$
\dot{\mathrm{q}}_{\mathrm{r}}(\mathrm{t})=\dot{\mathrm{q}}_{\mathrm{d}}(\mathrm{t})+\Lambda \mathrm{e}(\mathrm{t})
$$

where $\Lambda$ is a diagonal matrix of design parameters with big positive elements so that the system is BIBO stable. This matrix allows to filter errors so that no acceleration of errors $\ddot{e}(t)$ will appear in the error dynamic equation. The definition of filtered error $r(t)$ in terms of position and velocity errors can be obtained from (50) and (51)

$$
\mathrm{r}(\mathrm{t})=\dot{\mathrm{e}}(\mathrm{t})+\Lambda \mathrm{e}(\mathrm{t})
$$

Substituting $\mathrm{q}(\mathrm{t})$ from (50) into the plant, the error dynamic equation is derived.

$$
\mathrm{M}(\mathrm{q}) \dot{\mathrm{r}}=-\mathrm{C}(\mathrm{q}, \dot{\mathrm{q}}) \mathrm{r}+\mathrm{f}(\mathrm{x})-\tau+\tau_{\mathrm{d}}
$$

where $f(x)=M(q) \ddot{q}_{r}+C(q, \dot{q}) \dot{q}_{r}+G(q)+F(q, \dot{q})$ stands for non-linear terms to be compensated. This non-linear function could be parametrised by $x^{T}=\left(\mathrm{q}^{\mathrm{T}}, \dot{\mathrm{q}}^{\mathrm{T}}, \dot{\mathrm{q}}_{\mathrm{r}}^{\mathrm{T}}, \ddot{\mathrm{q}}_{\mathrm{r}}^{\mathrm{T}}\right)^{\mathrm{T}}$ or using the definition of $\dot{\mathrm{q}}_{\mathrm{r}}(\mathrm{t})$ in $(51)$ by $\mathrm{x}^{\mathrm{T}}=\left(\mathrm{e}^{\mathrm{T}}, \dot{\mathrm{e}}^{\mathrm{T}}, \mathrm{q}_{\mathrm{d}}^{\mathrm{T}}, \dot{\mathrm{q}}_{\mathrm{d}}^{\mathrm{T}}, \ddot{\mathrm{q}}_{\mathrm{d}}^{\mathrm{T}}\right)^{\mathrm{T}}$.

A structural property of robot manipulators is the linearity of parameters (LIP) (Craig, 1989), (Sciavicco, 2002). This means that non-linearities can be split up into a parameter vector $\mathrm{P}$ and a vector of basis functions $\Psi(x)$. Therefore the non-linearity function $f(x)$ can be expressed in this sense adding a term of error $\varepsilon$.

$$
\mathrm{f}(\mathrm{x})=\Psi\left(\mathrm{q}, \dot{\mathrm{q}}, \dot{\mathrm{q}}_{\mathrm{r}}, \ddot{\mathrm{q}}_{\mathrm{r}}\right) \mathrm{P}+\varepsilon
$$

Linearity of parameters (LIP) is a first assumption in most of the adaptive controllers. 
Proceeding in a similar way, the approximation of the non-linear function using estimation of the parameters $\hat{\mathrm{P}}$ can be represented by means of linearity of parameters.

$\hat{\mathrm{f}}(\mathrm{x})=\Psi\left(\mathrm{q}, \dot{\mathrm{q}}, \dot{\mathrm{q}}_{\mathrm{r}}, \ddot{\mathrm{q}}_{\mathrm{r}}\right) \hat{\mathrm{P}}$

\subsection{Controller Structure, Control Law and Updtating Law.}

Up unto this point, LIP property has been analyzed via fundamental matrices. The control approach employs an inertia-related linearization approach, i.e. a conservation of energy formulation, as an attempt to derive update laws and control laws. To be specific, it is required to define an inertia-related Lyapunov function in the stability analysis which utilizes physical properties inherent to a mechanical manipulator (such as those presented above). Thus, the stability of the tracking error system is ensured by formulating the adaptive update rule and by analyzing the stability of the tracking error system at the same time. It is well known that dynamic models even though quite complex are anyhow an idealization of reality. Specifically, robots show uncertainties that are mainly found from two sources: variability of parameters and nonlinearity terms in the system. One way of dealing with parametric uncertainties would be to use the inertia-related approach, see (Lewis et al., 2003). The benefits of this approach as compared to others is that avoids a direct measurement of acceleration and the invertibility of the generalized inertia matrix, which are restrictions of some controllers such as those inspired in the adaptive computedtorque approaches.

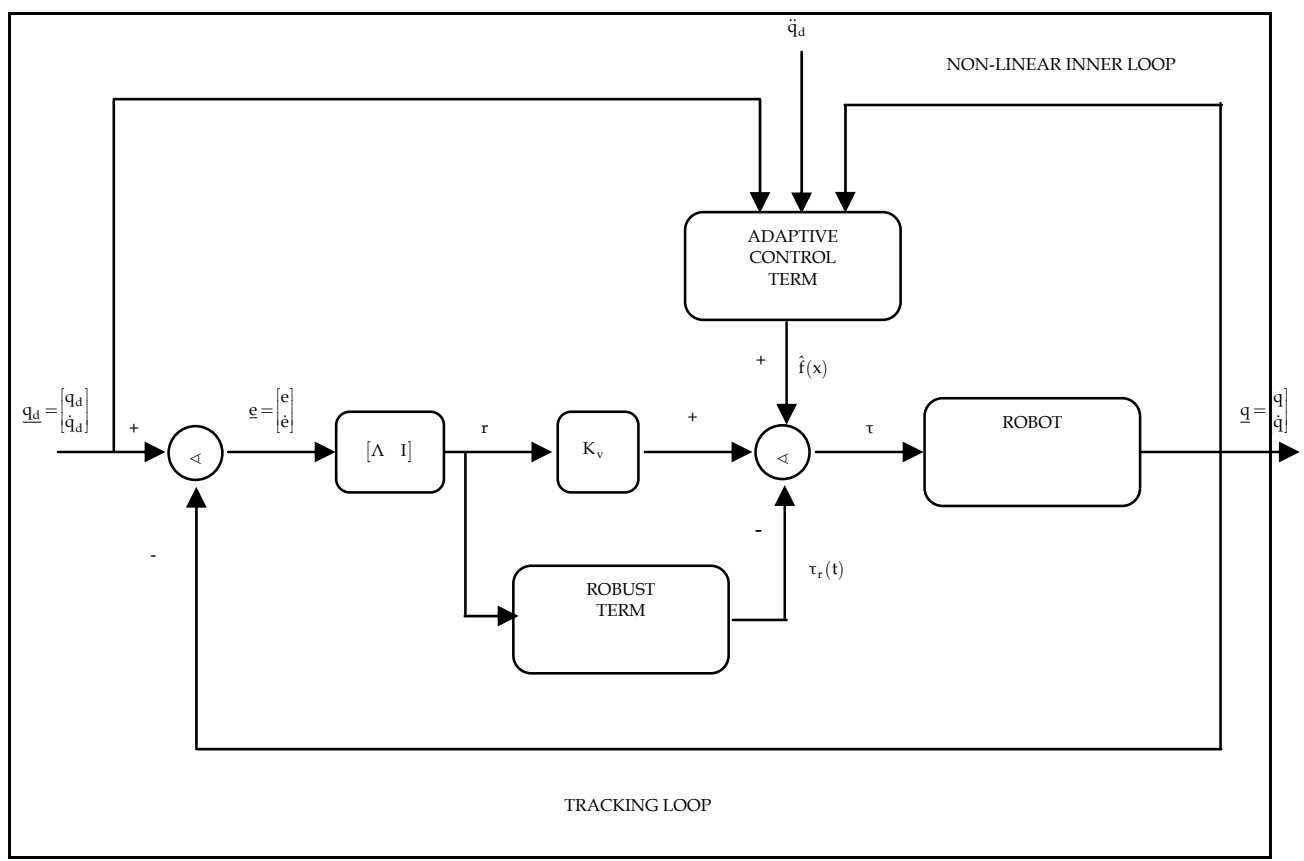

Fig. 1. Adaptive Control Structure 
The controller consists of three terms: a PD-controller to guarantee a good tracking performance, $\tau_{\mathrm{pd}}=\mathrm{K}_{\mathrm{v}} \mathrm{r}=\mathrm{K}_{\mathrm{v}}(\dot{\mathrm{e}}+\Lambda \mathrm{e})$, a compensator of non-linearities, $\tau_{\mathrm{nl}}=\hat{\mathrm{f}}$ and a robust controller to absorb unmodelled dynamics $\tau_{\mathrm{r}}$.

$$
\tau=\mathrm{K}_{\mathrm{v}} \mathrm{r}+\hat{\mathrm{f}}+\tau_{\mathrm{r}}
$$

where $\mathrm{K}_{\mathrm{v}}=\mathrm{K}_{\mathrm{v}}^{\mathrm{T}}>0$ is the gain matrix.

The control structure appears in figure 1. In this scheme, two loops can be spoted: an outer loop to track signals and an inner loop to compensate non-linearities. The inner loop is driven by an adaptive control and the outer loop is driven by a robust and PD terms.

An important feature of this class of controllers is that of being based on the all-important closed-loop error dynamics, which results from the substitution of the filtered tracking error into the robot dynamics

$$
\mathrm{M}(\mathrm{q}) \dot{\mathrm{r}}=-\mathrm{C}(\mathrm{q}, \dot{\mathrm{q}}) \mathrm{r}+\mathrm{f}(\mathrm{x})-\tau=-\mathrm{C}(\mathrm{q}, \dot{\mathrm{q}}) \mathrm{r}-\mathrm{K}_{\mathrm{v}} \mathrm{r}+\tilde{\mathrm{f}}(\mathrm{x})-\tau_{\mathrm{r}}
$$

where $\tilde{f}(x)=f(x)-\hat{f}(x)$ stands for the functional estimation error with $x$ being a vector of appropriate variables as shown below. The nominal nonlinearity $f$ can be computed as $\mathrm{f}\left(\mathrm{q}, \dot{\mathrm{q}}, \dot{\mathrm{q}}_{\mathrm{r}}, \ddot{\mathrm{q}}_{\mathrm{r}}\right)=\mathrm{M}(\mathrm{q}) \ddot{\mathrm{q}}_{\mathrm{r}}+\mathrm{C}(\mathrm{q}, \dot{\mathrm{q}}) \dot{\mathrm{q}}_{\mathrm{r}}+\mathrm{G}(\mathrm{q})$

where $\ddot{\mathrm{q}}_{\mathrm{r}}$ is the reference acceleration, $\ddot{\mathrm{q}}_{\mathrm{r}}(\mathrm{t}) \triangleq \ddot{\mathrm{q}}_{\mathrm{d}}(\mathrm{t})+\Lambda \dot{\mathrm{e}}(\mathrm{t})$, and $\dot{\mathrm{q}}_{\mathrm{r}}$ the reference velocity, $\dot{\mathrm{q}}_{\mathrm{r}}(\mathrm{t}) \triangleq \dot{\mathrm{q}}_{\mathrm{d}}(\mathrm{t})+\Lambda \mathrm{e}(\mathrm{t})$. The nonlinearity $\mathrm{f}$ can be conveniently partitioned into several smaller terms, resulting into an added controller structure

$f(x)=f_{m}(x)+f_{c}(x)+f_{g}(x)$

where $f_{g}(x)=G(q)$. The terms $f_{m}$ and $f_{c}$ can be defined in terms of $\ddot{q}_{r}$ and $\dot{q}_{r}$ as follows

$$
\begin{aligned}
\mathrm{f}_{\mathrm{m}}\left(\mathrm{q}, \ddot{\mathrm{q}}_{\mathrm{r}}\right) & =\mathrm{M}(\mathrm{q}) \ddot{\mathrm{q}}_{\mathrm{r}}=\Phi_{\mathrm{m}}\left(\mathrm{q}, \ddot{\mathrm{q}}_{\mathrm{r}}\right) \xi_{\mathrm{m}} \\
\mathrm{f}_{\mathrm{c}}\left(\mathrm{q}, \dot{\mathrm{q}}_{\mathrm{q}}, \ddot{\mathrm{q}}_{\mathrm{r}}\right) & =\mathrm{C}(\mathrm{q}, \dot{\mathrm{q}}) \dot{\mathrm{q}}_{\mathrm{r}}=\Phi_{\mathrm{c}}\left(\mathrm{q}, \dot{\mathrm{q}}, \ddot{\mathrm{q}}_{\mathrm{r}}\right) \xi_{\mathrm{m}} \\
\mathrm{f}_{\mathrm{g}}(\mathrm{q}) & =\mathrm{G}(\mathrm{q})=\Phi_{\mathrm{g}}(\mathrm{q}) \xi_{\mathrm{g}}
\end{aligned}
$$

where $\xi_{\mathrm{m}} \in \mathbb{R}^{1_{\mathrm{m}}}, \xi_{\mathrm{g}} \in \mathbb{R}^{1_{\mathrm{g}}}$ are parameter vectors and $\Phi_{\mathrm{m}}, \Phi_{\mathrm{c}}, \Phi_{\mathrm{g}}$ regression matrices.

Theorem 1: Let the desired trajectory $\mathrm{q}_{d}(\mathrm{t})$ bounded by $\mathrm{q}_{\mathrm{B}}$, i.e. $\left\|\mathrm{q}_{\mathrm{d}}(\mathrm{t})\right\| \leq \mathrm{q}_{\mathrm{B}}$. Suppose that the approximation error $\varepsilon$ and unmodeled disturbances $\tau_{d}(t)$ are upper bounded by $\varepsilon_{N}$ and $d_{B}$ respectively. Let the control law given by (52) with a robust term, $\tau_{\mathrm{r}}(\mathrm{t})=\mathrm{K}_{\mathrm{r}} \operatorname{sgn}(\mathrm{r}) \quad$ where $\mathrm{K}_{\mathrm{r}}=\operatorname{diag}\left(\mathrm{k}_{\mathrm{r}_{\mathrm{ii}}}\right)>0$ with $\mathrm{k}_{\mathrm{r}_{\mathrm{ii}}} \geq \varepsilon_{\mathrm{n}}+\mathrm{d}_{\mathrm{B}}$. The next parameter updating laws are considered 


$$
\begin{aligned}
& \dot{\hat{\xi}}_{\mathrm{m}}=\Gamma_{\mathrm{m}}\left(\Phi_{\mathrm{m}}^{\mathrm{T}}\left(\mathrm{q}, \ddot{\mathrm{q}}_{\mathrm{r}}\right)+\Phi_{\mathrm{c}}^{\mathrm{T}}\left(\mathrm{q}, \dot{\mathrm{q}}, \dot{\mathrm{q}}_{\mathrm{r}}\right)\right) \mathrm{r}= \\
& \quad=\Gamma_{\mathrm{m}}\left(\left(\ddot{\mathrm{q}}_{\mathrm{r}} \otimes \Psi_{\mathrm{m}}^{\mathrm{T}}(\mathrm{q})\right) \frac{1}{2}\left[\psi^{\mathrm{T}}\left(\mathrm{q}, \dot{\mathrm{q}}_{\mathrm{r}}\right)\left(\dot{\mathrm{q}} \otimes \mathrm{I}_{\mathrm{n}}\right)+\psi^{\mathrm{T}}(\mathrm{q}, \dot{\mathrm{q}})\left(\mathrm{I}_{\mathrm{n}^{2}}-\mathrm{P}(\mathrm{n}, \mathrm{n})\right)\left(\dot{\mathrm{q}}_{\mathrm{r}} \otimes \mathrm{I}_{\mathrm{n}}\right)\right]\right) \mathrm{r} \\
& \dot{\hat{\xi}}_{\mathrm{g}}=\Gamma_{\mathrm{g}} \Phi_{\mathrm{g}}^{\mathrm{T}}(\mathrm{q}) \mathrm{r}
\end{aligned}
$$

with $\Gamma_{\mathrm{m}}=\Gamma_{\mathrm{m}}^{\mathrm{T}}>0, \quad \Gamma_{\mathrm{g}}=\Gamma_{\mathrm{g}}^{\mathrm{T}}>0$ and $\Gamma_{\mathrm{f}}=\Gamma_{\mathrm{f}}^{\mathrm{T}}>0$ symmetric positive-definite constant matrices. Then tracking error $r(t) \rightarrow 0$ as $t \rightarrow \infty$ and parameters $\hat{\xi}_{\mathrm{m}}$ and $\hat{\xi}_{\mathrm{g}}$ are bounded $\left(\|\hat{\xi}\| \leq \xi_{\mathrm{B}}\right)$. It can be concluded that $\mathrm{e} \in \mathcal{L}_{2}^{\mathrm{n}} \cap \mathcal{L}_{\infty}^{\mathrm{n}}, e$ is continuous, $\mathrm{e}(\mathrm{t}) \rightarrow 0$ and $\dot{\mathrm{e}}(\mathrm{t}) \rightarrow 0$ as $\mathrm{t} \rightarrow \infty$; and $\tau$ is bounded.

Proof: Select the following inertia-related Lyapunov-like function:

$$
V=\frac{1}{2} r^{T} M(q) r+\frac{1}{2} \tilde{\xi}_{m}^{T} \Gamma_{m}^{-1} \tilde{\xi}_{m}+\frac{1}{2} \tilde{\xi}_{g}^{T} \Gamma_{g}^{-1} \tilde{\xi}_{g}
$$

where $\tilde{\xi}_{\mathrm{m}} \in \mathbb{R}^{1_{\mathrm{m}}}, \quad \tilde{\xi}_{\mathrm{g}} \in \mathbb{R}^{1_{\mathrm{g}}}$ are the parameter error vectors, $\Gamma_{\mathrm{m}} \in \mathrm{M}_{\mathrm{l}_{\mathrm{m}} \times \mathrm{l}_{\mathrm{m}}}(\mathbb{R})$ ， $\Gamma_{\mathrm{g}} \in \mathrm{M}_{\mathrm{l}_{\mathrm{g}} \times \mathrm{l}_{\mathrm{g}}}(\mathbb{R})$ diagonal, positive-definite matrices. Note that the term $\frac{1}{2} \mathrm{r}^{\mathrm{T}} \mathrm{M}(\mathrm{q}) \mathrm{r}$ stands for the kinetic energy with filtered error instead of joint velocities, and $\frac{1}{2} \tilde{\xi}^{\mathrm{T}} \Gamma^{-1} \tilde{\xi}$ is the energy attached to the non-linear terms to be compensated. It is noted that in (54), an energy for Coriolis/centripetal terms does not appear because these terms are obtained from inertia matrix approximation using Christoffel symbols of first kind. Matrices $\Gamma_{\mathrm{m}}, \Gamma_{\mathrm{g}}$ and $\Gamma_{\mathrm{f}}$ are diagonal and their non-null terms represent the learning rate of parameters to nominal values, for inertia and gravitational respectively.

Differentiating (54) with respect to time gives

$$
\dot{\mathrm{V}}=\mathrm{r}^{\mathrm{T}} \mathrm{M}(\mathrm{q}) \dot{\mathrm{r}}+\frac{1}{2} \mathrm{r}^{\mathrm{T}} \dot{\mathrm{M}}(\mathrm{q}) \mathrm{r}+\tilde{\xi}_{\mathrm{m}}^{\mathrm{T}} \Gamma_{\mathrm{m}}^{-1} \dot{\tilde{\xi}}_{\mathrm{m}}+\tilde{\xi}_{\mathrm{g}}^{\mathrm{T}} \Gamma_{\mathrm{g}}^{-1} \dot{\tilde{\xi}}_{\mathrm{g}}
$$

From (55) it is clear that we must substitute for the variable $\dot{r}$; therefore we must write the robot equation in terms of the variable $r$. Using (53) the robot dynamics can be rewritten as

$$
\mathrm{M}(\mathrm{q}) \dot{\mathrm{r}}=-\mathrm{C}(\mathrm{q}, \dot{\mathrm{q}}) \mathrm{r}-\mathrm{K}_{\mathrm{v}} \mathrm{r}+\tilde{\mathrm{f}}_{\mathrm{m}}\left(\mathrm{q}, \ddot{\mathrm{q}}_{\mathrm{r}}\right)+\tilde{\mathrm{f}}_{\mathrm{c}}\left(\mathrm{q}, \dot{\mathrm{q}}, \ddot{\mathrm{q}}_{\mathrm{r}}\right)+\tilde{\mathrm{f}}_{\mathrm{g}}(\mathrm{q})-\tau_{\mathrm{r}}
$$

The functional estimation error $\tilde{\mathrm{f}}(\mathrm{x})$ can be expressed in terms of regression emulators as indicated below

$$
\begin{aligned}
\tilde{\mathrm{f}}_{\mathrm{m}}\left(\mathrm{q}, \ddot{\mathrm{q}}_{\mathrm{r}}\right) & =\Phi_{\mathrm{m}}\left(\mathrm{q}, \ddot{\mathrm{q}}_{\mathrm{r}}\right) \xi_{\mathrm{m}}+\mathrm{E}_{\mathrm{m}}\left(\mathrm{q}, \ddot{\mathrm{q}}_{\mathrm{r}}\right) \\
\tilde{\mathrm{f}}_{\mathrm{c}}\left(\mathrm{q}, \dot{\mathrm{q}}, \ddot{\mathrm{q}}_{\mathrm{r}}\right) & =\Phi_{\mathrm{c}}\left(\mathrm{q}, \dot{\mathrm{q}}_{,}, \ddot{\mathrm{q}}_{\mathrm{r}}\right) \xi_{\mathrm{m}}+\mathrm{E}_{\mathrm{c}}\left(\mathrm{q}, \dot{\mathrm{q}}, \ddot{\mathrm{q}}_{\mathrm{r}}\right) \\
\tilde{\mathrm{f}}_{\mathrm{g}}(\mathrm{q}) & =\Phi_{\mathrm{g}}(\mathrm{q}) \xi_{\mathrm{g}}+\varepsilon_{\mathrm{g}}(\mathrm{q})
\end{aligned}
$$


Owing to the passivity property of robots $\dot{M}(q)-2 C(q, \dot{q})$ is a skew symmetric matrix and its quadratic form is zero:

$$
\dot{\mathrm{V}}(\mathrm{r})=-\mathrm{r}^{\mathrm{T}} \mathrm{K}_{\mathrm{v}} \mathrm{r}+\mathrm{r}^{\mathrm{T}}\left(\tilde{\mathrm{f}}_{\mathrm{m}}\left(\mathrm{q}, \ddot{\mathrm{q}}_{\mathrm{r}}\right)+\tilde{\mathrm{f}}_{\mathrm{c}}\left(\mathrm{q}, \dot{\mathrm{q}}_{,}, \ddot{\mathrm{q}}_{\mathrm{r}}\right)+\tilde{\mathrm{f}}_{\mathrm{g}}(\mathrm{q})\right)+\mathrm{r}^{\mathrm{T}} \tau_{\mathrm{r}}+\tilde{\xi}_{\mathrm{m}}^{\mathrm{T}} \Gamma_{\mathrm{m}}^{-1} \dot{\tilde{\xi}}_{\mathrm{m}}+\tilde{\xi}_{\mathrm{g}}^{\mathrm{T}} \Gamma_{\mathrm{g}}^{-1} \dot{\tilde{\xi}}_{\mathrm{g}}
$$

This is the same type of parametric separation that appears in the formulation of the adaptive computed-torque controller; however, note that regression matrices are not a function of joint acceleration $\ddot{q}$. Now, substituting (56) into (57) gives

$$
\begin{aligned}
\dot{\mathrm{V}}=-\mathrm{r}^{\mathrm{T}} \mathrm{K}_{\mathrm{v}} \mathrm{r} & +\left[\mathrm{r}^{\mathrm{T}}\left(\Phi_{\mathrm{m}}\left(\mathrm{q}, \ddot{\mathrm{q}}_{\mathrm{r}}\right)+\Phi_{\mathrm{c}}\left(\mathrm{q}, \dot{\mathrm{q}}, \dot{\mathrm{q}}_{\mathrm{r}}\right)\right)+\dot{\tilde{\xi}}_{\mathrm{m}}^{\mathrm{T}} \Gamma_{\mathrm{m}}^{-1}\right] \tilde{\xi}_{\mathrm{m}}+\left[\mathrm{r}^{\mathrm{T}} \Phi_{\mathrm{g}}(\mathrm{q})+\dot{\tilde{\xi}}_{\mathrm{g}} \Gamma_{\mathrm{g}}^{-1}\right] \tilde{\xi}_{\mathrm{g}} \\
& +\mathrm{r}^{\mathrm{T}}\left(\varepsilon\left(\mathrm{q}, \dot{\mathrm{q}}, \dot{\mathrm{q}}_{\mathrm{r}}, \ddot{\mathrm{q}}_{\mathrm{r}}\right)+\tau_{\mathrm{d}}\right)
\end{aligned}
$$

where

$$
\varepsilon\left(\mathrm{q}, \dot{\mathrm{q}}, \dot{\mathrm{q}}_{\mathrm{r}}, \ddot{\mathrm{q}}_{\mathrm{r}}\right)=\mathrm{E}_{\mathrm{m}}\left(\mathrm{q}, \ddot{\mathrm{q}}_{\mathrm{r}}\right)+\frac{1}{2}\left(\mathrm{E}_{\mathrm{D}}\left(\mathrm{q}, \dot{\mathrm{q}}_{\mathrm{r}}\right) \dot{\mathrm{q}}_{\mathrm{r}}-\mathrm{E}_{\mathrm{D}}^{\mathrm{T}}\left(\mathrm{q}, \dot{\mathrm{q}}_{\mathrm{r}}\right) \dot{\mathrm{q}}_{\mathrm{r}}+\mathrm{E}_{\mathrm{v}}(\mathrm{q}, \dot{\mathrm{q}}) \dot{\mathrm{q}}_{\mathrm{r}}\right)+\varepsilon_{\mathrm{g}}+\varepsilon_{\mathrm{f}}
$$

Now, the strategy consists of making zero the terms in brackets, which results in the following adaptive update rules:

$$
\begin{aligned}
& \dot{\hat{\xi}}_{\mathrm{m}}=\Gamma_{\mathrm{m}}\left(\Phi_{\mathrm{m}}^{\mathrm{T}}\left(\mathrm{q}, \ddot{\mathrm{q}}_{\mathrm{r}}\right)+\Phi_{\mathrm{c}}^{\mathrm{T}}\left(\mathrm{q}, \dot{\mathrm{q}}, \dot{\mathrm{q}}_{\mathrm{r}}\right)\right) \mathrm{r}= \\
& \quad=\Gamma_{\mathrm{m}}\left(\left(\ddot{\mathrm{q}}_{\mathrm{r}} \otimes \Psi_{\mathrm{m}}^{\mathrm{T}}(\mathrm{q})\right) \frac{1}{2}\left[\psi^{\mathrm{T}}\left(\mathrm{q}, \dot{\mathrm{q}}_{\mathrm{r}}\right)\left(\dot{\mathrm{q}} \otimes \mathrm{I}_{\mathrm{n}}\right)+\psi^{\mathrm{T}}(\mathrm{q}, \dot{\mathrm{q}})\left(\mathrm{I}_{\mathrm{n}^{2}}-\mathrm{P}(\mathrm{n}, \mathrm{n})\right)\left(\dot{\mathrm{q}}_{\mathrm{r}} \otimes \mathrm{I}_{\mathrm{n}}\right)\right]\right) \mathrm{r} \\
& \dot{\hat{\xi}}_{\mathrm{g}}=\Gamma_{\mathrm{g}} \Phi_{\mathrm{g}}^{\mathrm{T}}(\mathrm{q}) \mathrm{r}
\end{aligned}
$$

As long as $\varepsilon\left(\mathrm{q}, \dot{\mathrm{q}}, \dot{\mathrm{q}}_{\mathrm{r}}, \ddot{\mathrm{q}}_{\mathrm{r}}\right)$ and $\tau_{\mathrm{d}}(\mathrm{t})$ are bounded, $\dot{\mathrm{V}}(\mathrm{r})$ is also upper bounded.

$$
\dot{\mathrm{V}}(\mathrm{r}) \leq-\mathrm{K}_{\mathrm{v}_{\min }}\|\mathrm{r}\|^{2}+\mathrm{r}^{\mathrm{T}}\left(\varepsilon_{\mathrm{N}}+\mathrm{d}_{\mathrm{B}}\right)-\mathrm{r}^{\mathrm{T}} \mathrm{K}_{\mathrm{r}} \operatorname{sgn}(\mathrm{r})
$$

If $K_{r_{i i}} \geq \varepsilon_{n}+d_{B}$, and using lemma 6 in the appendix, $r^{T}\left(-K_{r} \operatorname{sgn}(r)+\varepsilon_{N}+d_{B}\right) \leq 0$, so that, $\dot{V}(r)$ is negative defined

$$
\dot{\mathrm{V}}(\mathrm{r}) \leq-\mathrm{K}_{\mathrm{v}_{\min }}\|\mathrm{r}\|^{2}
$$

Hence, $V(r)$ is a Lyapunov function, $V(r)>0$ and $\dot{V}(r) \leq 0$ so that stability in the sense of Lyapunov is guaranteed.

$$
\sigma_{\min }\left(K_{\mathrm{v}}\right) \int_{0}^{\mathrm{t}} \mathrm{r}^{\mathrm{T}} \mathrm{rd} \tau \leq \int_{0}^{\mathrm{t}} \mathrm{r}^{\mathrm{T}} \mathrm{K}_{\mathrm{v}} \mathrm{rd} \tau \leq \mathrm{V}(0)
$$


where $\sigma_{\min }\left(K_{\mathrm{v}}\right)$ is the minimum eigenvalue of $\mathrm{K}_{\mathrm{v}}$. Since $\mathrm{V}(0)$ and $\sigma_{\min }\left(\mathrm{K}_{\mathrm{v}}\right)$ are positive constants, $r(t)$ is a signal of finite energy $\left(r(t) \in \mathcal{L}_{2}^{n}\right)$ and this implies that is bounded. From lemma 7 in the appendix, e $\in \mathcal{L}_{2}^{\mathrm{n}} \cap \mathcal{L}_{\infty}^{\mathrm{n}}$, e is continuous and $\mathrm{e} \rightarrow 0$ as $\mathrm{t} \rightarrow \infty$, and $\dot{\mathrm{e}} \in \mathcal{L}_{2}^{\mathrm{n}}$. On the other hand, $\dot{\mathrm{V}}(\mathrm{r})$ is semidefinite negative, so that $0 \leq \mathrm{V}(\mathrm{r}(\mathrm{t})) \leq \mathrm{V}(\mathrm{r}(0)) \quad \forall \mathrm{t} \geq 0$. Since $\mathrm{V} \quad$ is lower bounded by zero and $\dot{\mathrm{V}}$ is nonpositive, it follows that $\mathrm{V}$ approaches a finite limit, which can be written as

$$
-\int_{0}^{\infty} \dot{\mathrm{V}}(\mathrm{r}) \mathrm{dt}<\infty
$$

and this implies that $\mathrm{V}(\mathrm{t}) \in \mathcal{L}_{\infty}$ and that $\hat{\xi}_{\mathrm{m}}$ and $\hat{\xi}_{\mathrm{g}}$ are bounded. Observing that $\mathrm{M}^{-1}(\mathrm{q})$, parameters $\xi_{\mathrm{m}}$ and $\xi_{\mathrm{g}}$, and regression functions $\Phi$ are bounded, and $\mathrm{r}(\mathrm{t}) \in \mathcal{L}_{2}^{\mathrm{n}}, \quad \mathrm{q}_{\mathrm{d}}, \dot{\mathrm{q}}_{\mathrm{d}}, \ddot{\mathrm{q}}_{\mathrm{d}}, \tau_{\mathrm{r}} \in \mathrm{L}_{\infty}^{\mathrm{n}}$, then from error filtered dynamics as given by (53) the boundedness of $\dot{\mathrm{r}}$ and $\tau(\mathrm{t})$ is verified $\left(\dot{\mathrm{r}}, \tau \in \mathrm{L}_{\infty}^{\mathrm{n}}\right)$. From the theorem 2 in the appendix and given that $\mathrm{e} \in \mathcal{L}_{2}^{\mathrm{n}}$, it follows that $\mathrm{r} \in \mathcal{L}_{2}^{\mathrm{n}} \cap \mathcal{L}_{\infty}^{\mathrm{n}}, \dot{\mathrm{r}} \in \mathcal{L}_{2}^{\mathrm{n}}, \mathrm{r} \quad$ is continuous and $\mathrm{r}(\mathrm{t}) \rightarrow 0$ as $\mathrm{t} \rightarrow \infty$. Hence, $\dot{\mathrm{e}} \rightarrow 0$ as $\mathrm{t} \rightarrow \infty$.

\subsection{Semi-global Stability. Initial Conditions Dependence.}

At this point a number of comments are in order. First of all it is interesting to explore indepth the initial conditions that must be satisfied by both the position errors and the velocity errors so as to guarantee the approximations to be valid. Thus, in the following remark these conditions are discussed from the Stone-Weierstrass theorem and from some results concerning with the stability of non-linear systems. The importance of developing this analysis stems from the fact that the approximations are only valid over a compact set whose size depends on a given desired accuracy.

It is assumed that the joint $i$ has physical limits $q_{\min _{i}}$ and $q_{\max _{i}}$ so that the workspace $\Omega_{\mathrm{q}}$ can be described as $\left[\mathrm{q}_{\min _{1}}, \mathrm{q}_{\max _{1}}\right] \times \ldots \times\left[\mathrm{q}_{\min _{\mathrm{n}}}, \mathrm{q}_{\max _{\mathrm{n}}}\right]$. For the subsequent discussion, it is worth considering the following weighting norm

$$
\|x\|_{\rho, \infty}=\max _{1 \leq i \leq n}\left\{\frac{\left|x_{i}\right|}{\rho_{i}}\right\}
$$

where $\rho \in \mathbb{R}^{\mathrm{n}}$ is a given vector. As a result, the compact set $\Omega_{\mathrm{q}}$ can be represented in the form of an $n-$ ball, i.e.

$$
\mathrm{B}\left(\mathrm{q}_{0}, \rho\right)=\left\{\mathrm{q} \in \mathbb{R}^{\mathrm{n}} \mid\left\|\mathrm{q}-\mathrm{q}_{0}\right\|_{\rho, \infty} \leq 1\right\}
$$

where 


$$
\begin{aligned}
q_{0_{i}} & =\frac{q_{\min _{i}}+q_{\max _{i}}}{2} \\
\rho_{i} & =\frac{q_{\max _{i}}-q_{\min _{i}}}{2}
\end{aligned}
$$

Remark As it was claimed above, the desired trajectories remain bounded for all time. This means that the vector $\mathrm{q}_{\mathrm{d}}(\mathrm{t})$ is in the compact set $\Omega_{\mathrm{d}}=\left\{\mathrm{q}_{\mathrm{d}} \in \mathbb{R}^{\mathrm{n}}\left\|\mathrm{q}_{\mathrm{d}}\right\| \leq \mathrm{q}_{\mathrm{B}}\right\}$ for an appropriate upper bound $q_{\mathrm{B}}$. From the Stone-Weierstrass theorem, it is possible to find an emulator with a sufficient number of nodes and, with suitable parameters, satisfying the following condition

$$
\left\|\mathrm{f}_{\mathrm{m}}\left(\mathrm{q}, \ddot{\mathrm{q}}_{\mathrm{r}}\right)-\Phi_{\mathrm{m}}\left(\mathrm{q}, \ddot{\mathrm{q}}_{\mathrm{r}}\right) \xi_{\mathrm{m}}\right\| \leq\left\|\mathrm{E}_{\mathrm{m}}\left(\mathrm{q}, \ddot{\mathrm{q}}_{\mathrm{r}}\right)\right\|
$$

for a given vector $\ddot{\mathrm{q}}_{\mathrm{r}}$, and over a compact set $\Omega_{\mathrm{m}}$ including the workspace of the robot manipulator. In this, it is convenient to recall that $E_{m}\left(q, \ddot{q}_{r}\right)=\varepsilon_{m}(q) \ddot{q}_{r}$ where $\varepsilon_{\mathrm{m}}(\mathrm{q}) \in \mathbb{R}^{\mathrm{n} \times \mathrm{n}}$ denotes the estimation error for the inertia generalized matrix. Note that the compact set $\Omega_{\mathrm{q}}$ denotes an operation region of interest in which the system works on. This implies that the obtained result is regionally stable in the sense that all the states $q(t)$ must be guaranteed within the compact $\Omega_{\mathrm{q}}$. Furthermore, this compact set should include the space of desired trayectories, i.e. $\quad \Omega_{\mathrm{d}} \subseteq \Omega_{\mathrm{q}}$. In a similar way, it can be stated the following validity regions for the approximation of fundamental matrices $M_{D}$ and $M_{V}$

$$
\begin{array}{r}
\left\|\mathrm{M}_{\mathrm{D}}(\mathrm{q}, \dot{\mathrm{q}}) \dot{\mathrm{q}}_{\mathrm{r}}-\Phi_{\mathrm{D}}\left(\mathrm{q}, \dot{\mathrm{q}}, \dot{\mathrm{q}}_{\mathrm{r}}\right) \xi_{\mathrm{m}}\right\| \leq\left\|\mathrm{E}_{\mathrm{D}}(\mathrm{q}, \dot{\mathrm{q}}) \dot{\mathrm{q}}_{\mathrm{r}}\right\| \\
\left\|\mathrm{M}_{\mathrm{V}}(\mathrm{q}, \dot{\mathrm{q}}) \dot{\mathrm{q}}_{\mathrm{r}}-\Phi_{\mathrm{v}}\left(\mathrm{q}, \dot{\mathrm{q}}, \dot{\mathrm{q}}_{\mathrm{r}}\right) \xi_{\mathrm{m}}\right\| \leq\left\|\mathrm{E}_{\mathrm{V}}(\mathrm{q}, \dot{\mathrm{q}}) \dot{\mathrm{q}}_{\mathrm{r}}\right\| \\
\left\|\mathrm{M}_{\mathrm{D}}^{\mathrm{T}}(\mathrm{q}, \dot{\mathrm{q}}) \dot{\mathrm{q}}_{\mathrm{r}}-\left(\dot{\mathrm{q}} \otimes \mathrm{I}_{\mathrm{n}}\right) \mathrm{P}(\mathrm{n}, \mathrm{n}) \psi\left(\mathrm{q}, \dot{\mathrm{q}}_{\mathrm{r}}\right) \xi_{\mathrm{m}}\right\| \leq\left\|\mathrm{E}_{\mathrm{D}}^{\mathrm{T}}(\mathrm{q}, \dot{\mathrm{q}}) \dot{\mathrm{q}}_{\mathrm{r}}\right\|
\end{array}
$$

for a given vectors $\dot{\mathrm{q}}, \dot{\mathrm{q}}_{\mathrm{r}} \in \mathbb{R}^{\mathrm{n}}$ and for all $\mathrm{q}$ in $\Omega_{\mathrm{q}}$ describing the validity region. It is clear from this discussion that the ideal parameters are derived as the following optimization problem

$$
\xi_{\mathrm{m}} \triangleq \min _{\substack{\xi \in \mathbb{R}^{\mathrm{L}^{\mathrm{n}}} \\ \mathrm{q} \in \Omega_{\mathrm{q}}}}\left\{\left\|\mathrm{f}_{\mathrm{m}}\left(\mathrm{q}, \ddot{\mathrm{q}}_{\mathrm{r}}\right)+\mathrm{f}_{\mathrm{c}}\left(\mathrm{q}, \dot{\mathrm{q}}, \dot{\mathrm{q}}_{\mathrm{r}}\right)-\Phi_{\mathrm{m}}\left(\mathrm{q}, \ddot{\mathrm{q}}_{\mathrm{r}}\right) \xi_{\mathrm{m}}-\Phi_{\mathrm{c}}\left(\mathrm{q}, \dot{\mathrm{q}}, \ddot{\mathrm{q}}_{\mathrm{r}}\right) \xi_{\mathrm{m}}\right\|\right\}
$$

In the last expression $\mathrm{L}_{\mathrm{m}}$ denotes the number of nodes required for the inertia approximation.

The same observations can be done for the gravitational vector $G(q)$. Thus, the validity region $\Omega_{\mathrm{g}}$ for the approximation of this term is determined by the condition $\left\|\mathrm{G}(\mathrm{q})-\Phi_{\mathrm{g}}(\mathrm{q}) \xi_{\mathrm{g}}\right\| \leq\left\|\varepsilon_{\mathrm{g}}(\mathrm{q})\right\|$

for all $\mathrm{q} \in \Omega_{\mathrm{q}}$. Evidently, for this region to be useful, it should be included the workspace 
$\Omega_{\mathrm{q}}$. Just like for the inertia terms, the ideal parameters are derived as

$$
\xi_{\mathrm{g}} \triangleq \min _{\substack{\mathrm{W} \in \mathbb{R}^{\mathrm{L}_{\mathrm{m}} \times \mathrm{n}} \\ \mathrm{q} \in \Omega_{\mathrm{q}}}}\left\{\left\|G(\mathrm{q})-\Phi_{\mathrm{g}}(\mathrm{q}) \xi_{\mathrm{g}}\right\|\right\}
$$

It is known that the error $\mathrm{e}(\mathrm{t})$ is connected to the filtered tracking error $\mathrm{r}(\mathrm{t})$ via a transfer function $\quad \mathrm{G}_{\mathrm{r}}(\mathrm{s})=\mathrm{sI}+\Lambda$ with $\quad \Lambda \in \mathbb{R}^{\mathrm{n} \times \mathrm{n}} \quad$ a Hurwitz matrix. From lemma 8 in the appendix, it should be clear that being $G_{\mathrm{r}}(\mathrm{s})$ a strictly proper, exponentially stable transfer function, then $\mathrm{r} \in \mathcal{L}_{2}^{\mathrm{n}} \Rightarrow \mathrm{e} \in \mathcal{L}_{2}^{\mathrm{n}} \cap \mathcal{L}_{\infty}^{\mathrm{n}}, \quad \dot{\mathrm{e}} \in \mathcal{L}_{2}^{\mathrm{n}}, \quad \mathrm{e} \quad$ is continuous and $\mathrm{e}(\mathrm{t}) \rightarrow 0$ as $\mathrm{t} \rightarrow \infty$. If in addition $\mathrm{r} \rightarrow 0 \quad$ as $\mathrm{t} \rightarrow \infty$, then $\dot{\mathrm{e}} \rightarrow 0$. Furthermore, it is assumed that the filtered tracking error $r \in \mathcal{L}_{\infty}^{\mathrm{n}}$, i.e. there exists a constant $b_{r} \in \mathbb{R}$ such that $\|r\| \leq b_{r}$. Actually, this condition should be guaranteed by the controller. If the differential equation describing the closed-loop filtered tracking error dynamics is solved, it is easy to see the following relationship

$$
\mathrm{e}(\mathrm{t})=\mathrm{e}^{-\Lambda\left(\mathrm{t}-\mathrm{t}_{0}\right)} \mathrm{e}\left(\mathrm{t}_{0}\right)+\int_{\mathrm{t}_{0}}^{\mathrm{t}} \mathrm{e}^{-\Lambda(\mathrm{t}-\tau)} \mathrm{r}(\tau) \mathrm{d} \tau
$$

Due to $\|\mathrm{r}\|_{\rho, \infty} \leq \mathrm{b}_{\mathrm{r}, \infty}$, being $\quad \mathrm{b}_{\mathrm{r}, \infty} \in \mathbb{R} \quad$ a constant, it is straightforward to derive an upper bound for the error norm

$$
\|\mathrm{e}(\mathrm{t})\|_{\rho, \infty} \leq\left\|\mathrm{e}\left(\mathrm{t}_{0}\right)\right\|_{\rho, \infty}+\frac{\mathrm{b}_{\mathrm{r}, \infty}}{\lambda_{\min }\{\Lambda\}}\left\|\mathrm{e}^{-\Lambda\left(\mathrm{t}-\mathrm{t}_{\mathrm{o}}\right)}-1\right\|_{\rho, \infty} \leq\left\|\mathrm{e}\left(\mathrm{t}_{0}\right)\right\|_{\rho, \infty}+\frac{\mathrm{b}_{\mathrm{r}, \infty}}{\lambda_{\min }\{\Lambda\}}
$$

The universal property of approximation holds so long as $\mathrm{q}(\mathrm{t}) \in \Omega_{\mathrm{q}}$ or equivalently whenever $\left\|\mathrm{q}(\mathrm{t})-\mathrm{q}_{0}\right\|_{\rho_{, \infty}} \leq 1$. Applying the triangle inequality to (60) and from the boundedness of the desired trajectory (i.e. $\left\|q_{d}(t)-q_{0}\right\|_{\rho, \infty} \leq q_{d, \infty}$ ), it is not difficult to write the following $\left\|\mathrm{q}(\mathrm{t})-\mathrm{q}_{0}\right\|_{\rho, \infty} \leq \mathrm{q}_{\mathrm{d}, \infty}+\left\|\mathrm{e}\left(\mathrm{t}_{0}\right)\right\|_{\rho, \infty}+\frac{\mathrm{b}_{\mathrm{r}, \infty}}{\lambda_{\min }\{\Lambda\}} \leq 1$.

Note that owing to $\Omega_{\mathrm{d}} \subseteq \Omega_{\mathrm{q}}$, the bound $\mathrm{q}_{\mathrm{d}, \infty}$ satisfies the condition $\mathrm{q}_{\mathrm{d}, \infty} \leq 1$. Now the radius $b_{r, \infty}$ is determined,

$$
\mathrm{b}_{\mathrm{r}, \infty} \leq \lambda_{\min }\{\Lambda\}\left(1-\mathrm{q}_{\mathrm{d}, \infty}-\left\|\mathrm{e}\left(\mathrm{t}_{0}\right)\right\|_{\rho, \infty}\right)
$$

As a consequence, the initial filterd tracking error must satisfy the condition $\left\|r\left(t_{0}\right)\right\| \leq b_{r, \infty}$ for the constant $b_{r, \infty}$ given in (61).

It is known that $\left\|\mathrm{r}\left(\mathrm{t}_{0}\right)\right\|_{\rho, \infty} \leq\left\|\dot{\mathrm{e}}\left(\mathrm{t}_{0}\right)\right\|_{\rho, \infty}+\lambda_{\max }\{\Lambda\}\left\|\mathrm{e}\left(\mathrm{t}_{0}\right)\right\|_{\rho, \infty}$ and then, the condition $\left\|\mathrm{r}\left(\mathrm{t}_{0}\right)\right\| \leq \mathrm{b}_{\mathrm{r}, \infty}$ is held whenever 


$$
\left\|\dot{\mathrm{e}}\left(\mathrm{t}_{0}\right)\right\|_{\rho, \infty}+\lambda_{\max }\{\Lambda\}\left\|\mathrm{e}\left(\mathrm{t}_{0}\right)\right\|_{\rho, \infty} \leq \lambda_{\min }\{\Lambda\}\left(1-\mathrm{q}_{\mathrm{d}, \infty}-\left\|\mathrm{e}\left(\mathrm{t}_{0}\right)\right\|_{\rho, \infty}\right)
$$

It is concluded that the initial errors $\mathrm{e}\left(\mathrm{t}_{0}\right)$ and $\dot{\mathrm{e}}\left(\mathrm{t}_{0}\right)$ must verify the inequality (62), where the constants $\Lambda$ and $\mathrm{q}_{\mathrm{d}, \infty}$ are known a priori.

Remark If the robust term is removed from the control law, it is necessary to account for an additional assumption of persistence of excitation (PE) on the signals $\Phi_{\mathrm{g}}$ and $\Phi_{\mathrm{m}}$. In this case, the variation of the energy is upper bounded in the following way

$$
\dot{\mathrm{V}} \leq-\lambda_{\min }\left\{\mathrm{K}_{\mathrm{v}}\right\}\|\mathrm{r}\|^{2}+\|\mathrm{r}\|\left(\varepsilon_{\mathrm{N}}+\mathrm{d}_{\mathrm{B}}\right)
$$

Obviously the energy is decreasing as long as the size of the filtered tracking error remains greater than a constant, i.e.

$$
\|\mathrm{r}\| \geq \frac{\varepsilon_{\mathrm{N}}+\mathrm{d}_{\mathrm{B}}}{\lambda_{\min }\left\{\mathrm{K}_{\mathrm{v}}\right\}}
$$

As it was pointed out in the previous discussion, the validity of the approximation holds throughout whenever $r \in \Omega_{r}=\left\{r \in \mathbb{R}^{n} \mid\|r\|_{\rho, \infty} \leq b_{r, \infty}\right\}$, being $b_{r, \infty}$ given in (61). Under these considerations, it is easy to derive a suitable selection for the derivative gains as

$$
\lambda_{\min }\left\{\mathrm{K}_{\mathrm{v}}\right\} \geq \frac{\left(\varepsilon+\mathrm{d}_{\mathrm{B}}\right)}{\lambda_{\min }\{\Lambda\}\left(1-\mathrm{q}_{\mathrm{d}, \infty}-\left\|\mathrm{e}\left(\mathrm{t}_{0}\right)\right\|_{\rho, \infty}\right)}
$$

Unfortunately, the tracking errors do not vanish, but are bounded by small enough values. Since $\|\mathrm{r}\|_{\rho, \infty} \leq \mathrm{b}_{\mathrm{r}, \infty}$, the errors $\mathrm{e}$ and $\dot{\mathrm{e}}$ are also guaranteed to be bounded. Additionally to this result, the boundedness of the desired trajectory also implies that the states $q$ and $\dot{\mathrm{q}}$ are bounded. To complete the analysis the boundedness of the parameters is now explored. To this purpose, it is worth considering the dynamics relative to $\tilde{\xi}_{\mathrm{m}}$ and $\tilde{\xi}_{\mathrm{g}}$

$$
\left\{\begin{array}{c}
\dot{\tilde{\xi}}_{\mathrm{m}}=-\Gamma_{\mathrm{m}}\left(\left(\ddot{\mathrm{q}}_{\mathrm{r}} \otimes \Psi_{\mathrm{m}}^{\mathrm{T}}(\mathrm{q})\right) \frac{1}{2}\left[\psi^{\mathrm{T}}\left(\mathrm{q}, \dot{\mathrm{q}}_{\mathrm{r}}\right)\left(\dot{\mathrm{q}} \otimes \mathrm{I}_{\mathrm{n}}\right)+\psi^{\mathrm{T}}(\mathrm{q}, \dot{\mathrm{q}})\left(\mathrm{I}_{\mathrm{n}^{2}}-\mathrm{P}(\mathrm{n}, \mathrm{n})\right)\left(\dot{\mathrm{q}}_{\mathrm{r}} \otimes \mathrm{I}_{\mathrm{n}}\right)\right]\right) \mathrm{r} \\
\dot{\tilde{\xi}}_{\mathrm{g}}=-\Gamma_{\mathrm{g}} \Phi_{\mathrm{g}}^{\mathrm{T}}(\mathrm{q}) \mathrm{r} \\
\mathrm{y}_{\mathrm{m}}=\Phi_{\mathrm{m}}\left(\mathrm{q}, \ddot{\mathrm{q}}_{\mathrm{r}}\right) \tilde{\xi}_{\mathrm{m}} \\
\mathrm{y}_{\mathrm{g}}=\Phi_{\mathrm{g}}(\mathrm{q}) \tilde{\xi}_{\mathrm{g}}
\end{array}\right.
$$

It can be shown that the boundedness can be obtained by reformulating the problem in terms of the Kronecker product. This consideration leads to the following vector dynamics 


$$
\begin{gathered}
\left(\begin{array}{l}
\hat{\xi}_{\mathrm{m}} \\
\hat{\xi}_{\mathrm{g}}
\end{array}\right)=\left(\begin{array}{c}
\Gamma_{\mathrm{m}}\left(\left(\ddot{\mathrm{q}}_{\mathrm{r}} \otimes \Psi_{\mathrm{m}}^{\mathrm{T}}(\mathrm{q})\right) \frac{1}{2}\left[\psi^{\mathrm{T}}\left(\mathrm{q}, \dot{\mathrm{q}}_{\mathrm{r}}\right)\left(\dot{\mathrm{q}} \otimes \mathrm{I}_{\mathrm{n}}\right)+\psi^{\mathrm{T}}(\mathrm{q}, \dot{\mathrm{q}})\left(\mathrm{I}_{\mathrm{n}^{2}}-\mathrm{P}(\mathrm{n}, \mathrm{n})\right)\left(\dot{\mathrm{q}}_{\mathrm{r}} \otimes \mathrm{I}_{\mathrm{n}}\right)\right]\right) \mathrm{r} \\
\Gamma_{\mathrm{g}} \Phi_{\mathrm{g}}^{\mathrm{T}}(\mathrm{q}) \mathrm{r}
\end{array}\right) \\
\left(\begin{array}{c}
\mathrm{y}_{\mathrm{m}} \\
\mathrm{y}_{\mathrm{g}}
\end{array}\right)=\mathrm{Q}\left(\mathrm{q}, \dot{\mathrm{q}}, \dot{\mathrm{q}}_{\mathrm{r}}, \ddot{\mathrm{q}}_{\mathrm{r}}\right)\left(\begin{array}{l}
\hat{\xi}_{\mathrm{m}} \\
\hat{\xi}_{\mathrm{g}}
\end{array}\right)
\end{gathered}
$$

where the matrix $Q$ is defined as

$$
\mathrm{Q} \triangleq\left(\begin{array}{cc}
\Phi_{\mathrm{m}}\left(\mathrm{q}, \ddot{\mathrm{q}}_{\mathrm{r}}\right) & 0 \\
0 & \Phi_{\mathrm{g}}(\mathrm{q})
\end{array}\right)
$$

Now, the PE condition is equivalent to the persistence of excitation of $\Phi_{\mathrm{g}}(\mathrm{q})$ and of $\Phi_{\mathrm{m}}\left(\mathrm{q}, \ddot{\mathrm{q}}_{\mathrm{r}}\right)$, and consequently to the uniform complete observability of this system. From the lemma 9, the boundedness of $y_{m}(t), y_{g}(t)$, and $r(t)$ insures the boundedness of $\tilde{\xi}_{\mathrm{m}}$ and of $\tilde{\xi}_{\mathrm{g}}$, and then the boundedness of $\hat{\xi}_{\mathrm{m}}$ and of $\hat{\xi}_{\mathrm{g}}$. With reference to the theorem 3, due to $\|\mathrm{r}\|$ is greater than a constant, it can be asserted that the system is ultimately uniformly bounded (UUB).

Remark: Defining the state $\mathrm{x}=\left(\mathrm{r}^{\mathrm{T}}, \tilde{\xi}_{\mathrm{m}}^{\mathrm{T}}, \tilde{\xi}_{\mathrm{g}}^{\mathrm{T}}\right)^{\mathrm{T}}$ the energy can be written as

where

$$
\mathrm{V}(\mathrm{x})=\frac{1}{2} \mathrm{x}^{\mathrm{T}} \mathrm{Px}
$$

$$
\mathrm{P}=\left(\begin{array}{ccc}
\mathrm{M}(\mathrm{q}) & 0_{\mathrm{n} \times \mathrm{nL}_{\mathrm{m}}} & 0_{\mathrm{n} \times \mathrm{nL}} \\
0_{\mathrm{nL}_{\mathrm{m}} \times \mathrm{n}} & \Phi_{\mathrm{m}}\left(\mathrm{q}, \ddot{\mathrm{q}}_{\mathrm{r}}\right) & 0_{\mathrm{nL}_{\mathrm{m}} \times \mathrm{nL}_{\mathrm{g}}} \\
0_{\mathrm{nL}_{\mathrm{g}} \times \mathrm{n}} & 0_{\mathrm{nL}_{\mathrm{g}} \times \mathrm{nL}_{\mathrm{m}}} & \Phi_{\mathrm{g}}(\mathrm{q})
\end{array}\right)
$$

In this case the energy is lower and upper bounded,

$$
\frac{1}{2}\|\mathrm{x}\|^{2} \leq \mathrm{V}(\mathrm{x}) \leq \frac{1}{2}\|\mathrm{x}\|^{2}
$$

where the constants $\lambda_{1}$ and $\lambda_{2}$ are defined as follows

$$
\begin{aligned}
& \lambda_{1}=\min \left\{\lambda_{\min }\{\mathrm{M}(\mathrm{q})\}, \frac{1}{\lambda_{\max }\left\{\Gamma_{\mathrm{m}}\right\}}, \frac{1}{\lambda_{\max }\left\{\Gamma_{\mathrm{g}}\right\}}\right\} \\
& \lambda_{2}=\max \left\{\lambda_{\max }\{\mathrm{M}(\mathrm{q})\}, \frac{1}{\lambda_{\min }\left\{\Gamma_{\mathrm{m}}\right\}}, \frac{1}{\lambda_{\min }\left\{\Gamma_{\mathrm{g}}\right\}}\right\}
\end{aligned}
$$

Applying the passivity property of robot manipulators on the variation of the energy with 
respect to time leads to the following expression

$$
\dot{\mathrm{V}}=-\mathrm{r}^{\mathrm{T}} \mathrm{K}_{\mathrm{v}} \mathrm{r}+\mathrm{r}^{\mathrm{T}}\left(\varepsilon\left(\mathrm{q}, \dot{\mathrm{q}}, \dot{\mathrm{q}}_{\mathrm{r}}, \ddot{\mathrm{q}}_{\mathrm{r}}\right)+\tau_{\mathrm{d}}\right)+\left(\mathrm{r}^{\mathrm{T}} \Phi_{\mathrm{m}}\left(\mathrm{q}, \ddot{\mathrm{q}}_{\mathrm{r}}\right)+\dot{\tilde{\xi}}_{\mathrm{m}}^{\mathrm{T}} \Gamma_{\mathrm{m}}^{-1}\right) \tilde{\xi}_{\mathrm{m}}+\left(\mathrm{r}^{\mathrm{T}} \Phi_{\mathrm{g}}(\mathrm{q})+\dot{\tilde{\xi}}_{\mathrm{g}}^{\mathrm{T}} \Gamma_{\mathrm{g}}^{-1}\right) \tilde{\xi}_{\mathrm{g}}
$$

Folding the parameter updating law (62) into the last expression, the variation of the energy becomes

$$
\dot{\mathrm{V}}=-\mathrm{r}^{\mathrm{T}} \mathrm{K}_{\mathrm{v}} \mathrm{r}+\mathrm{r}^{\mathrm{T}}\left(\varepsilon\left(\mathrm{q}, \dot{\mathrm{q}}, \dot{\mathrm{q}}_{\mathrm{r}}, \ddot{\mathrm{q}}_{\mathrm{r}}\right)+\tau_{\mathrm{d}}\right)
$$

Assuming that the external disturbance torque and the functional reconstruction error are uniformly bounded, i.e. $\left\|\tau_{d}\right\| \leq \mathrm{d}_{\mathrm{B}}$ and $\left\|\varepsilon\left(\mathrm{q}, \dot{\mathrm{q}}, \dot{\mathrm{q}}_{\mathrm{r}}, \ddot{\mathrm{q}}_{\mathrm{r}}\right)\right\| \leq \varepsilon_{\mathrm{B}}$, the power will be bounded by

$$
\dot{\mathrm{V}} \leq-\lambda_{\min }\left\{\mathrm{K}_{\mathrm{v}}\right\}\|\mathrm{r}\|^{2}+\left(\mathrm{d}_{\mathrm{B}}+\varepsilon_{\mathrm{B}}\right)\|\mathrm{r}\|
$$

with $\lambda_{\min }\left\{\mathrm{K}_{\mathrm{v}}\right\} \quad$ representing the minimum eigenvalue of the gain matrix $\mathrm{K}_{\mathrm{v}}$. Owing to $\varepsilon_{B}$ and $d_{B}$ are constants, $\dot{V}$ is semidefinite negative as long as $\|\mathrm{r}\|>\frac{\left(\mathrm{d}_{B}+\varepsilon_{B}\right)}{\lambda_{\min }\left\{\mathrm{K}_{\mathrm{v}}\right\}}$. Hence,

$$
\frac{\left(\mathrm{d}_{\mathrm{B}}+\varepsilon_{\mathrm{B}}\right)}{\lambda_{\min }\left\{\mathrm{K}_{\mathrm{v}}\right\}}<\|\mathrm{x}(\mathrm{t})\|<\infty
$$

Invoking the theorem 4 in the appendix, it is concluded that

$$
\|\mathrm{x}(\mathrm{t})\|<\frac{\left(\mathrm{d}_{\mathrm{B}}+\varepsilon_{\mathrm{B}}\right)}{\lambda_{\min }\left\{\mathrm{K}_{\mathrm{v}}\right\}} \sqrt{\frac{\lambda_{2}}{\lambda_{1}}} \quad \forall \mathrm{t} \in\left[\mathrm{t}_{0}+\mathrm{T}, \infty\right)
$$

where $0 \leq \mathrm{T}<\infty$. In this way, it is stated the ultimately uniformly boundedness of $\mathrm{x}$.

Remark: In the ideal case, when $\varepsilon_{\mathrm{N}}=\mathrm{d}_{\mathrm{B}}=0$, it is easy to show the asymptotic convergence. In this case the variation of the Lyapunov energy in (59) turns to be

$$
\dot{\mathrm{V}}(\mathrm{r})=-\mathrm{r}^{\mathrm{T}} \mathrm{K}_{\mathrm{v}} \mathrm{r}
$$

Note that in this case no robust term is necessary to be introduced into the control law since there is no functional reconstruction errors nor external disturbances. It can be shown that the second differentiation $\ddot{V}(r)=-2 r^{T} K_{v} \dot{r} \quad$ is also bounded and uniform continuity of $\mathrm{V}(\mathrm{r})$ is guaranteed. Since $\mathrm{V}(\mathrm{r})>0, \dot{\mathrm{V}}(\mathrm{x}, \mathrm{t})$ uniformly continuous and non-positive, involking lemma 7 in the appendix, it is easy to show that $\dot{V}$ vanishes as $t$ goes to infinity. Indeed, by using Barbalat's lemma it can be concluded that $\dot{V}(r) \rightarrow 0$ as $t \rightarrow \infty$ and that $\mathrm{r}(\mathrm{t}) \rightarrow 0$. Hence, $\dot{\mathrm{e}}(\mathrm{t}) \rightarrow 0$ as $\mathrm{t} \rightarrow \infty$.

The parameter tuning algorithm is hardly a continuous-time backpropagation algorithm. These parameters are initialized to zero so that there is no preliminary off-line phase and in 
the first steps of working the controller behaves just as a PD controller. If the gain $K_{v}$ is considered to be large, the closed loop error remains bounded and this implies the stabilization of the whole system. This initialization is very important since it is not necessary to choose initial parameters that make stable the system. It is well known that this task is very complex to do.

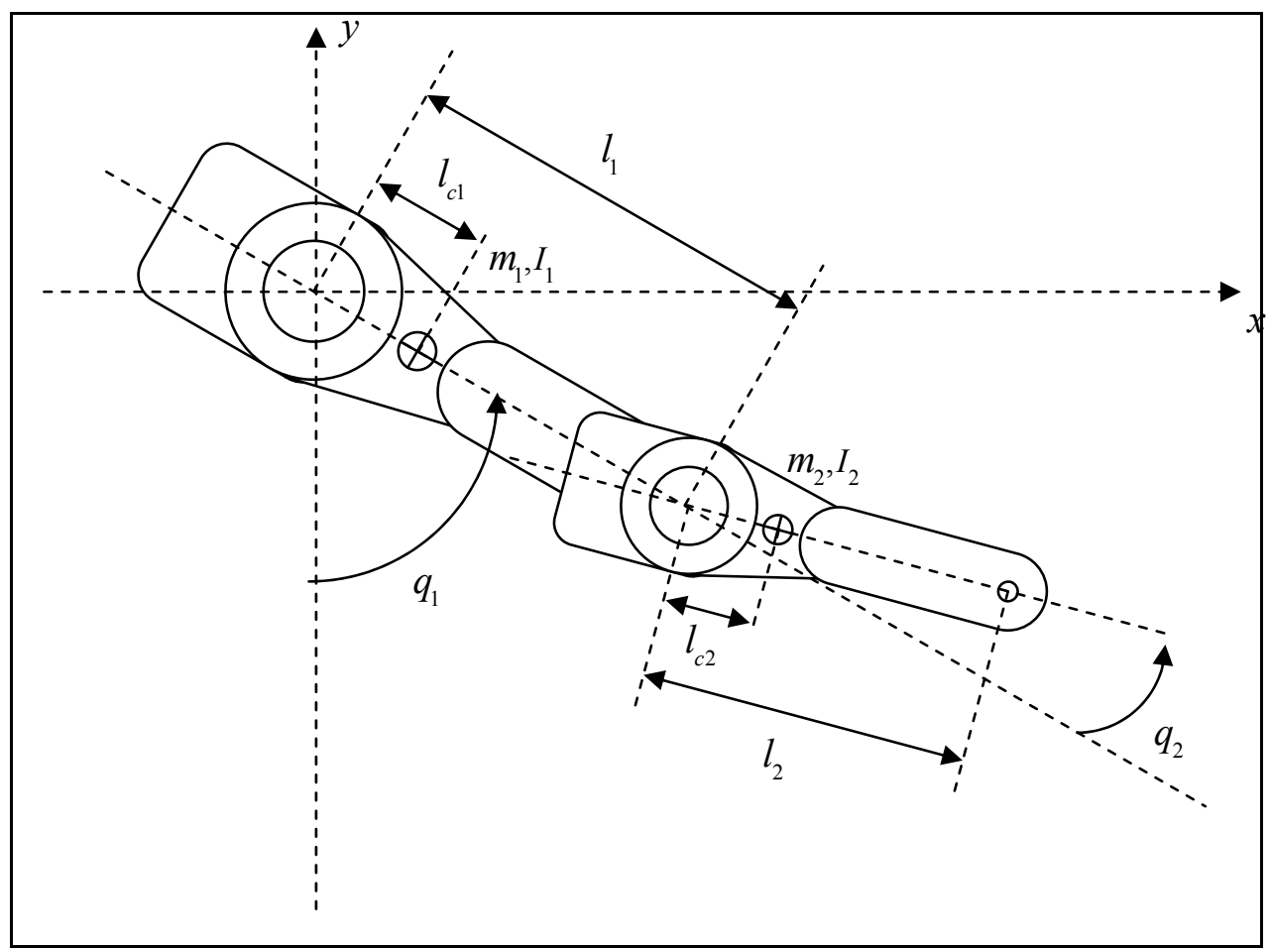

Fig. 2. Two-Link Planar Elbow Arm

\section{Results}

A planar two-link arm robot is used here as a platform to demonstrate the effectiveness of the adaptive controller. These kind of robots are used widely in the literature to get proof of the effectiveness of the controllers and appears in figure 2. Dynamics can be found in the literature (Spong \& Vidyasagar, 1989), (Lewis et al. ,2003) and no friction is taken into account in the model. The generalized inertia matrix is given by

$$
M(q)=\left(\begin{array}{cc}
m_{1} l_{c_{1}}^{2}+m_{2} l_{1}^{2}+I_{1} & m_{2} l_{1} l_{c_{2}} \cos \left(q_{2}-q_{1}\right) \\
m_{2} 1_{1} l_{c_{2}} \cos \left(q_{2}-q_{1}\right) & m_{2} l_{c_{2}}^{2}+I_{2}
\end{array}\right)
$$

where $\mathrm{q}^{\mathrm{T}}=\left(\mathrm{q}_{1}, \mathrm{q}_{2}\right)^{\mathrm{T}}$ is the joint variable, $\mathrm{m}_{1}, \mathrm{~m}_{2}$ are the masses of the links, $\mathrm{l}_{1}, \mathrm{l}_{2}$ the 
length of the links, $1_{\mathrm{c}_{1}}, 1_{\mathrm{c}_{2}}$ the position of the center of mass respect to the frame attached to the link and $I_{1}, I_{2}$ are the inertia about the Z-axis for each link.

The construction of the approximating function in the controller is illustrated here. From (Ge et al., 1998) a superset of basis functions $\varphi_{m}(q)$ for $M(q)$ is found and this set described completely the robotic system.

$$
\varphi_{\mathrm{m}}(\mathrm{q})=\left(1, \sin \left(\mathrm{q}_{1}\right), \sin \left(\mathrm{q}_{2}\right), \cos \left(\mathrm{q}_{1}\right), \cos \left(\mathrm{q}_{2}\right)\right)^{\mathrm{T}} \in \mathbb{R}^{5}
$$

In practise, only a subset of elements is necessary to describe the whole system and this means that $\mathrm{M}(\mathrm{q})$ is over parametrised. From (64) the activation function for inertia matrix, $\gamma_{m}\left(q, \ddot{q}_{r}\right)$ is built as $\gamma_{m}\left(q, \ddot{q}_{r}\right)=\ddot{q}_{r} \otimes \varphi_{m}(q)$. The dimension of $\gamma_{m}\left(q, \ddot{q}_{r}\right)$ means that the number of nodes required to approximate inertia matrix is 10 .

Coriolis-centripetal matrix is carried out from (58) and this implies to calculate the Jacobian matrix $\Psi(\mathrm{q}, \mathrm{x})=\sum_{\mathrm{i}=1}^{\mathrm{n}}\left(\mathbf{x} \otimes \frac{\partial \varphi_{\mathrm{m}}(\mathrm{q})}{\partial \mathrm{q}_{\mathrm{i}}}\right) \mathrm{e}_{\mathrm{i}}^{\mathrm{T}}$. This Jacobian is applied to vectors of dimension 2 in order to work out the Coriolis/centripetal matrix so that the number of nodes is also 10 .

The desired trajectory is chosen as a periodic sinusoid with amplitud 1 and frequency 1 $\mathrm{rad} / \mathrm{sec}$.

$$
\begin{aligned}
& \mathrm{q}_{\mathrm{d}_{1}}(\mathrm{t})=\sin (\mathrm{t}) \\
& \mathrm{q}_{\mathrm{d}_{2}}(\mathrm{t})=\cos (\mathrm{t})
\end{aligned}
$$

This provides bounded signals for position, velocity and acceleration. It is assumed that initially there is no knowledge about the system so that all the weights are initialized to zero.

The robot parameters are $\mathrm{l}_{1}=\mathrm{l}_{2}=1 \mathrm{~m}$ and the mases are $\mathrm{m}_{1}=0.8 \mathrm{~kg}, \mathrm{~m}_{2}=2.3 \mathrm{~kg}$. The gains of the controller were chosen as $K_{\mathrm{v}}=\operatorname{diag}(20,20), \Gamma_{\mathrm{m}}=\Gamma_{\mathrm{g}}=\Gamma_{\mathrm{f}}=\operatorname{diag}(50,50)$, $\Lambda=\operatorname{diag}(5,5)$. It is assumed the next initial conditions for signals and estimations, $\mathrm{q}(0)=0, \dot{\mathrm{q}}(0)=0, \hat{\mathrm{m}}_{1}(0)=0, \hat{\mathrm{m}}_{2}(0)=0$. In this scheme all the parameters are initialized at zero so that there is no preliminary off-line learning phase. The signal tracking and weight tuning works together on-line. The main benefit of this initialization is the independence of the controller as regards the initial parameters skipping the task of finding initial stabilizing parameters as necessary in other control techniques.

The whole system was simulated in SIMULINK using Runge-Kutta method with an integration fixed step of $\Delta t=10^{-3} \mathrm{sec}$ and a simulation range from 0 to $20 \mathrm{sec}$. The response of the controller with parameter tuning (e.g. Theorem 1) appears in figure 3.

It is noted that no knowledge of the dynamics is needed for adaptive control and a good tracking performance is obtained as observed in figure 4 . Position error signals remains in a bound band of $\pm 5 \%$ respect to the equilibrium point. In this figure an exponential convergence response of the system is showed with a setting time about 5 seconds. It is possible to improve the tracking performance by increasing the gains of the controller. 
Therefore, it is concluded that the designed neurocontroller provides a good tracking of desired trajectories.

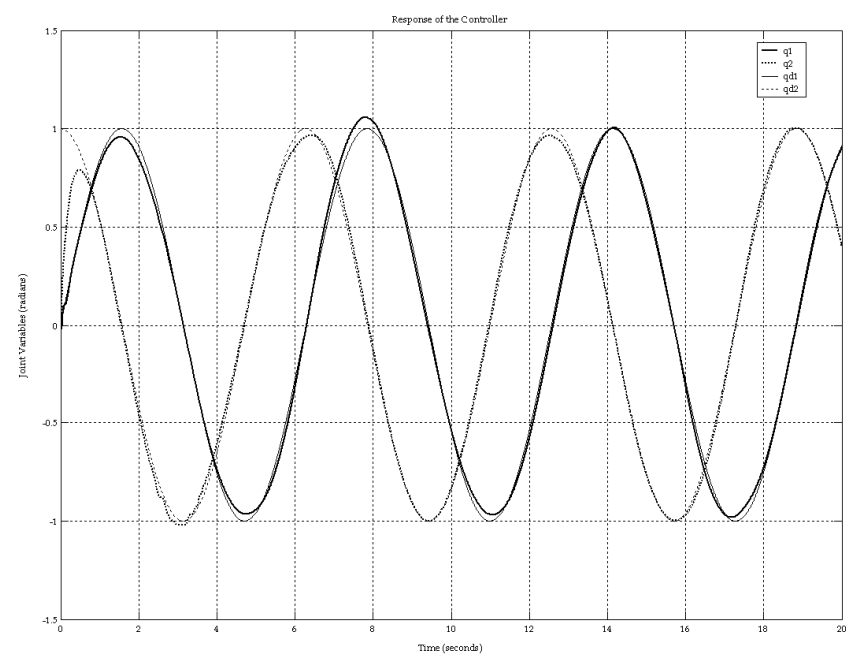

Fig. 3. Response of the Adaptive Controller with Gradient-Type tuning. Actual and desired joint angles.

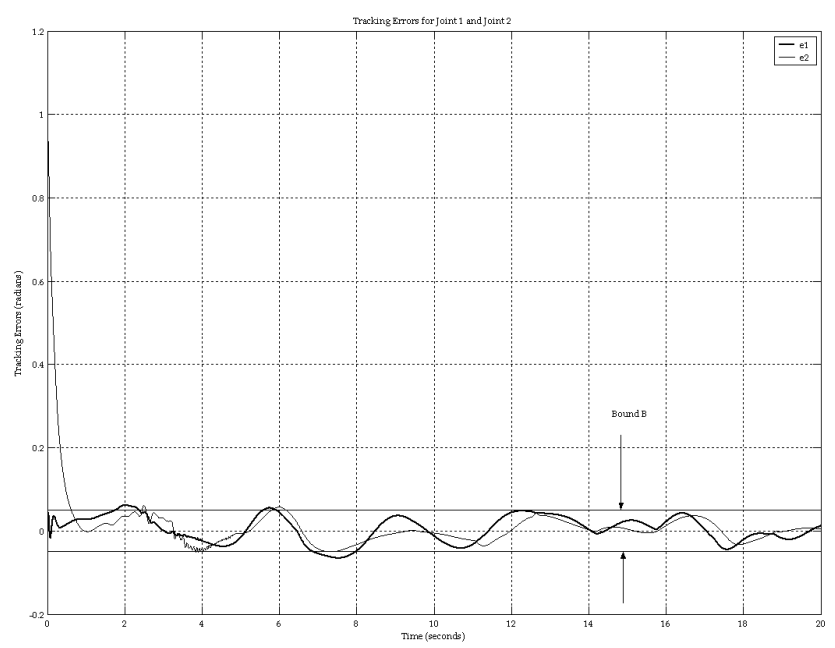

Fig. 4. Response of the controller with gradient-type parameter tuning. Representation of tracking errors 


\section{Appendix}

Lemma 6: For $\mathrm{K}=\operatorname{diag}\left(\mathrm{K}_{\mathrm{ii}}\right) \in \mathrm{R}^{\mathrm{n} \times \mathrm{n}}$ and $\mathrm{d}=\left(\mathrm{d}_{1}, \mathrm{~d}_{2}, \ldots, \mathrm{d}_{\mathrm{n}}\right)^{\mathrm{T}} \in \mathrm{R}^{\mathrm{n}}$, if $\mathrm{u}=-\operatorname{Ksgn}(\mathrm{x})$ and $\mathrm{k}_{\mathrm{ii}} \geq\left|\mathrm{d}_{\mathrm{i}}\right|$ then $\mathrm{x}^{\mathrm{T}} \mathrm{M}(\mathrm{u}-\mathrm{d}) \leq 0 \quad$ (Ge et al., 1998).

Lemma 7: Let $V(x, t)$ be a Lyapunov function so that $V(x, t)>0, \dot{V}(x, t) \leq 0$. If $\dot{V}(x, t)$ is uniformly continuous (Lewis et al., 2003), then

$$
\dot{\mathrm{V}}(\mathrm{x}, \mathrm{t}) \rightarrow 0 \text { as } \mathrm{t} \rightarrow \infty
$$

The following theorem is very important in control of non-linear systems, and is due to Desoer and Vidyasagar, cf. (Desoer \& Vidyasagar, 2008)

Theorem 2: Let the closed-loop transfer function $\mathrm{H}(\mathrm{s}) \in \mathbb{R}^{\mathrm{n} \times \mathrm{n}}(\mathrm{s})$ be exponentially stable and strictly proper, and $h(t)$ the corresponding impulse response (obtained by evaluating the inverse Laplace transform of $\mathrm{H}(\mathrm{s}))$. If $\mathrm{u} \in \mathcal{L}_{2}^{\mathrm{n}}$, then $\mathrm{y}=\mathrm{h} * \mathrm{u} \in \mathcal{L}_{2}^{\mathrm{n}} \cap \mathcal{L}_{\infty}^{\mathrm{n}}, \dot{\mathrm{y}} \in \mathcal{L}_{2}^{\mathrm{n}}, \mathrm{y}$ is continuous and $\mathrm{y}(\mathrm{t}) \rightarrow 0$ as $\mathrm{t} \rightarrow \infty$, where $\mathrm{h} * \mathrm{u}$ denotes the convolution product of $\mathrm{h}$ and $\mathrm{u}$.

On the basis of this theorem, it is possible to state the following lemma, (Ge et al., 1998).

Lemma 8: Let $\mathrm{e}(\mathrm{t})=\mathrm{h}(\mathrm{t}) * \mathrm{r}(\mathrm{t})$, where $\mathrm{h}=\mathcal{L}^{-1}\{\mathrm{H}(\mathrm{s})\}$ and $\mathrm{H}(\mathrm{s})$ is an $\mathrm{n} \times \mathrm{n}$ strictly proper, exponentially stable transfer function. Then $\mathrm{r} \in \mathcal{L}_{2}^{\mathrm{n}} \Rightarrow \mathrm{e} \in \mathcal{L}_{2}^{\mathrm{n}} \cap \mathcal{L}_{\infty}^{\mathrm{n}}, \quad \dot{\mathrm{e}} \in \mathcal{L}_{2}^{\mathrm{n}}$, e is continuous and $\mathrm{e}(\mathrm{t}) \rightarrow 0$ as $\mathrm{t} \rightarrow \infty$. If in addition $\mathrm{r} \rightarrow 0$ as $\mathrm{t} \rightarrow \infty$, then $\dot{\mathrm{e}} \rightarrow 0$. (Ge et al., 1998).

Theorem 3 (UUB by Lyapunov Analysis): If for system

$$
\dot{x}=f(x, t)+g(t)
$$

there exists a function $V(x, t)$ with continuous partial derivatives such that for $x$ in a compact set $S \subseteq \mathbb{R}^{\mathrm{n}}$

$$
\begin{gathered}
\mathrm{V}(\mathrm{x}, \mathrm{t}) \text { is positive definite, } \mathrm{V}(\mathrm{x}, \mathrm{t})>0 \\
\dot{\mathrm{V}}(\mathrm{x}, \mathrm{t})<0 \text { for }\|\mathrm{x}\|>\mathrm{R}
\end{gathered}
$$

for some $\mathrm{R}>0$, such that the ball of radius $\mathrm{R}$ is contained in $\mathrm{S}$, then the system is UUB and the norm of the state is bounded to within a neighborhood of $R$.

The following theorem is a modified version of the uniformly ultimately boundedness theorem of Corless and Leitmann, cf. (Corless \& Leitmann, 1981). For more insights the reader may refer to theorems 1 and 2 in (Dawson et al., 1990) or the theorem 2.15. p. 65 in (Qu, 1998).

Theorem 4: If $\mathrm{V}$ is a Lyapunov candidate function for any given continuous-time system with the properties

$$
\lambda_{1}\|x(t)\|^{2} \leq \mathrm{V}(\mathrm{x}(\mathrm{t})) \leq \lambda_{2}\|\mathrm{x}(\mathrm{t})\|^{2}
$$




$$
\dot{\mathrm{V}}(\mathrm{x}(\mathrm{t}))<0, \text { if } \eta_{2}>\|\mathrm{x}(\mathrm{t})\|>\eta_{1}
$$

where

$$
\eta_{2}>\eta_{1} \sqrt{\frac{\lambda_{2}}{\lambda_{1}}}
$$

then

$$
\|x(t)\|<\eta_{1} \sqrt{\frac{\lambda_{2}}{\lambda_{1}}} \forall t \in\left[t_{0}+T, \infty\right)
$$

where $\mathrm{T}$ is a finite positive constant.

The following lemma allows to connect the uniform complete observability (UCO) to the boundedness of the states, (Lewis et al., 1999).

Lemma 9 (Technical Lemma): Consider the linear time-varying system $(0, B(t), C(t))$ defined by

$$
\begin{aligned}
& \dot{x}=B(t) u \\
& y=C(t) x
\end{aligned}
$$

with $\mathrm{x} \in \mathbb{R}^{\mathrm{n}}, \mathrm{u} \in \mathbb{R}^{\mathrm{m}}, \mathrm{y} \in \mathbb{R}^{\mathrm{p}}$ and the elements of $\mathrm{B}(\mathrm{t})$ and $\mathrm{C}(\mathrm{t})$ piecewise continuous functions of time. Since the state transition matrix is the identity matrix, the observability grammian is

$$
N\left(t, t_{0}\right)=\int_{t_{0}}^{t} C^{T}(\tau) C(\tau) d \tau
$$

Let the system be uniformly completely observable with $B(t)$ bounded. Then if $u(t)$ and $\mathrm{y}(\mathrm{t})$ are bounded, the state $\mathrm{x}(\mathrm{t})$ is bounded.

\section{References}

Corless, M. and Leitmann, G. (1981). Continuous State Feedback Guaranteeing Uniform Ultimate Boundness for Uncertain Dynamics Systems. IEEE Transactions on Automatic Control, Vol.26, No. 5, (October 1981) (1139- 1144), ISSN 0018-9286

Dawson, D. M., Qu, Z., Lewis, F. L., and Dorsey, J. F. (1990). Robust Control for the Tracking of Robot Motion. International Journal of Control, Vol.52, No. 3, (1990) (581-595), ISSN 0020-7179

Desoer, C. A., and Vidyasagar, M. (2008). Feedback Systems: Input-Output Properties, Society for Industrial and Applied Mathematics, ISBN 978-0898716702

Ge, S. S., Lee, T. H. and Harris, C. J. (1998). Adaptive Neural Network Control of Robotic Manipulators, World Scientific Publishing Company, ISBN 978-9810234522, London

Horn, R. A., and Johnson, C. R. (1999). Topics in Matrix Analysis, Cambridge University Press, ISBN 978-0521467131

Lewis, F. L., Jagannathan, S. and Yesildirek, A. (1999). Neural Network Control of Robot Manipulators and Nonlinear Systems, Taylor and Francis Ltd., ISBN 978-0748405961 
Lewis, F. L., Dawson, D. M. and Abdallah, C. T. (2003). Robot Manipulator Control: Theory and Practice, Marcel Dekker Inc., ISBN 978-0824740726.

Mulero-Martínez, J.I. (2007). Bandwidth of Mechanical Systems and Design of Emulators with RBF. Neurocomputing, Vol.70, No.7-9, (2007) (1453-1465), ISSN 0925-2312

Mulero-Martínez, J.I. (2007a). An Improved Dynamic Neurocontroller Based on Christoffel Symbols. IEEE Transactions on Neural Networks, Vol.18, No.3, (May 2007) (865-879), ISSN 1045-9227

Mulero-Martínez, J.I. (2007b). Uniform Bounds of the Coriolis/Centripetal Matrix of Serial Robot Manipulators. IEEE Transactions on Robotics, Vol.23, No.5, (October 2007) (1083-1089), ISSN 1552-3098

Mulero-Martínez, J.I. (2009). A New Factorization of the Coriolis/Centripetal Matrix. Robotica, Vol.27, No.5, (September 2009) (689-700), ISSN 0263-5747

Qu, Z. (1998). Robust Control of Nonlinear Uncertain Systems, John Wiley and Sons, ISBN 9780471115892

Slotine, J.J. and Li, W. (1991) Applied Nonlinear Control, Prentice-Hall, ISBN 978-0130408907

Spong, M. W. and Vidyasagar, M. (1989). Robot Dynamics and Control, John Wiley and Sons Inc., ISBN 978-0471612438.

Wen, J. T. (1990). A Unified Perspective on Robot Control: The Energy Lyapunov Function Approach. International Journal of Adaptive Control and Signal Processing, Vol.4, No. 6 (November, 1990) (487-500) 


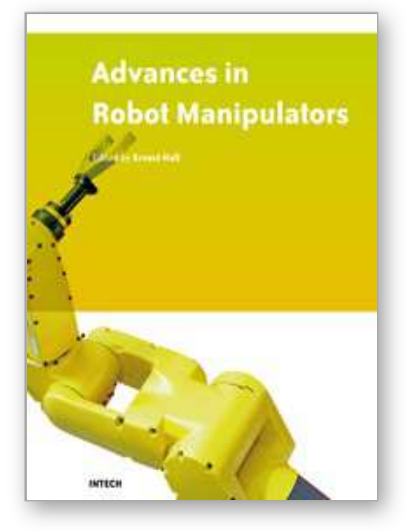

\author{
Advances in Robot Manipulators \\ Edited by Ernest Hall
}

ISBN 978-953-307-070-4

Hard cover, 678 pages

Publisher InTech

Published online 01, April, 2010

Published in print edition April, 2010

The purpose of this volume is to encourage and inspire the continual invention of robot manipulators for science and the good of humanity. The concepts of artificial intelligence combined with the engineering and technology of feedback control, have great potential for new, useful and exciting machines. The concept of eclecticism for the design, development, simulation and implementation of a real time controller for an intelligent, vision guided robots is now being explored. The dream of an eclectic perceptual, creative controller that can select its own tasks and perform autonomous operations with reliability and dependability is starting to evolve. We have not yet reached this stage but a careful study of the contents will start one on the exciting journey that could lead to many inventions and successful solutions.

\title{
How to reference
}

In order to correctly reference this scholarly work, feel free to copy and paste the following:

Juan Ignacio Mulero-Martinez (2010). Design of Adaptive Controllers based on Christoffel Symbols of First Kind, Advances in Robot Manipulators, Ernest Hall (Ed.), ISBN: 978-953-307-070-4, InTech, Available from: http://www.intechopen.com/books/advances-in-robot-manipulators/design-of-adaptive-controllers-based-onchristoffel-symbols-of-first-kind

\section{INTECH}

open science | open minds

\section{InTech Europe}

University Campus STeP Ri

Slavka Krautzeka 83/A

51000 Rijeka, Croatia

Phone: +385 (51) 770447

Fax: +385 (51) 686166

www.intechopen.com

\section{InTech China}

Unit 405, Office Block, Hotel Equatorial Shanghai

No.65, Yan An Road (West), Shanghai, 200040, China

中国上海市延安西路65号上海国际贵都大饭店办公楼 405 单元

Phone: +86-21-62489820

Fax: +86-21-62489821 
(C) 2010 The Author(s). Licensee IntechOpen. This chapter is distributed under the terms of the Creative Commons Attribution-NonCommercialShareAlike-3.0 License, which permits use, distribution and reproduction for non-commercial purposes, provided the original is properly cited and derivative works building on this content are distributed under the same license. 